\title{
ADULTS WHO CO-RESIDE AND THE YOUNG ADULTHOOD FACTORS THAT \\ LEAD THEM THERE
}

\author{
By \\ LESLIE HAUGHEY \\ Bachelor of Science in Human Development \\ and Family Science \\ Oklahoma State University \\ Stillwater, Oklahoma \\ 2008
}
Submitted to the Faculty of the Graduate College of the Oklahoma State University in partial fulfillment of the requirements for the Degree of MASTER OF SCIENCE December, 2011




\section{ADULTS WHO CO-RESIDE AND THE YOUNG ADULTHOOD FACTORS THAT LEAD THEM THERE}

Thesis Approved:

Dr. Michael J. Merten

Thesis Adviser

Dr. Carolyn S. Henry

Dr. Karina M. Shreffler

Dr. Sheryl A. Tucker

Dean of the Graduate College 
This research uses data from Add Health, a program project directed by Kathleen Mullan Harris and designed by J. Richard Udry, Peter S. Bearman, and Kathleen Mullan Harris at the University of North Carolina at Chapel Hill, and funded by grant P01HD31921 from the Eunice Kennedy Shriver National Institute of Child Health and Human Development, with cooperative funding from 23 other federal agencies and foundations. Special acknowledgment is due Ronald R. Rindfuss and Barbara Entwisle for assistance in the original design. Information on how to obtain the Add Health data files is available on the Add Health website (http://www.cpc.unc.edu/addhealth). No direct support was received from grant P01-HD31921 for this analysis. 


\section{TABLE OF CONTENTS}

Chapter

Page

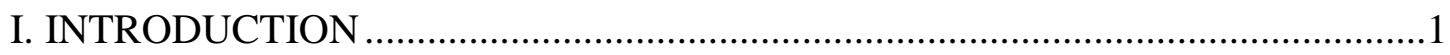

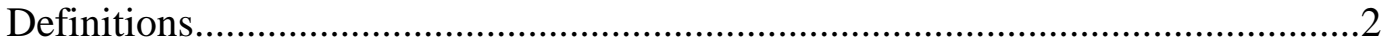

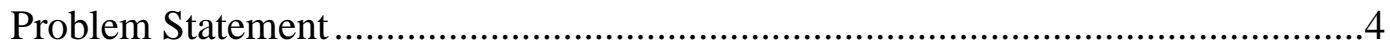

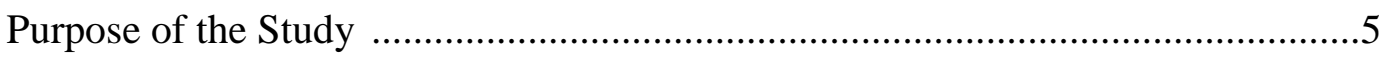

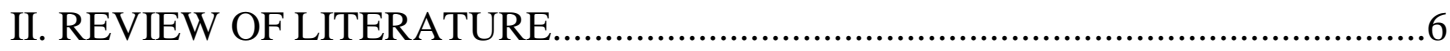

Theoretical Framework .............................................................................6

Precocious Life Events and Co-residency ......................................................13

Precocious Life Events and Well-Being ........................................................14

Precocious Life Events and Young Adult Status Attainment.............................17

Precocious Life Events and Parental Relationship Quality ...............................20

Depressive Symptoms and Co-residency.........................................................21

Young Status Adult Attainment and Co-residency ........................................21

Parental Relationship Quality and Co-residency ..........................................22

Family Economic Hardship and Co-residency ...............................................22

Parental Marital Stability and Co-residency .................................................24

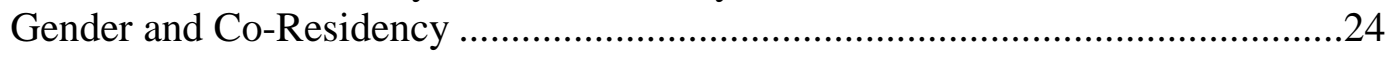

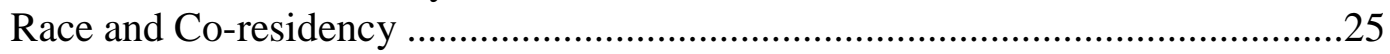

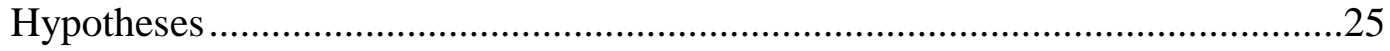

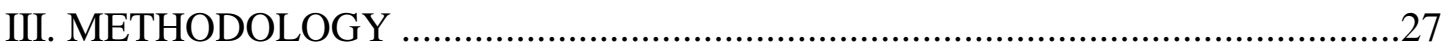

Sample

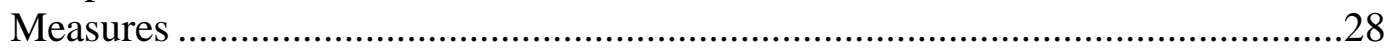

Co-residence with Parents...............................................................................28

Adolescent Precocious Life Events ...............................................................28

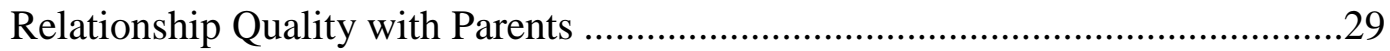

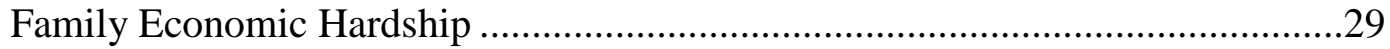

Biological Parents Married ...................................................................... 30

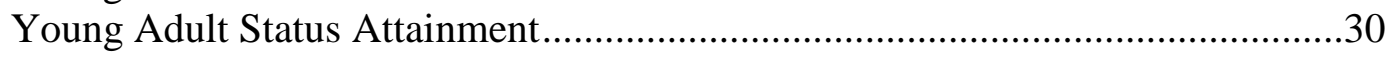

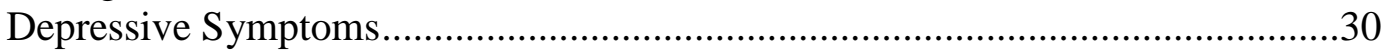

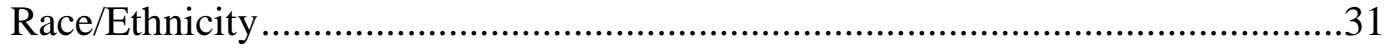

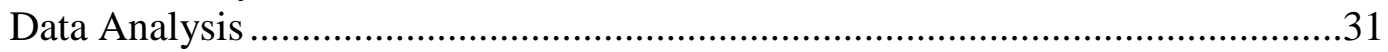

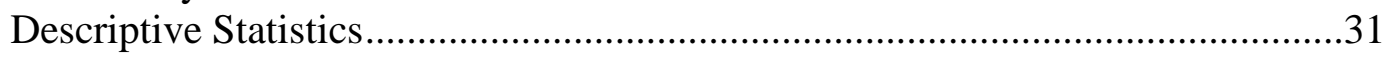

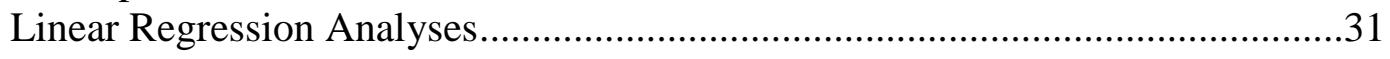

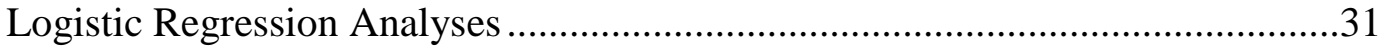




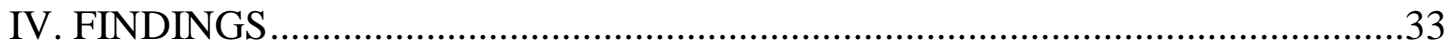

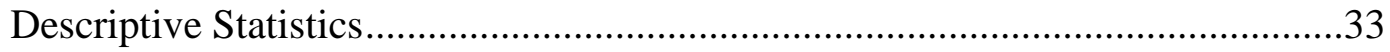

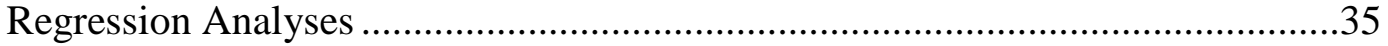

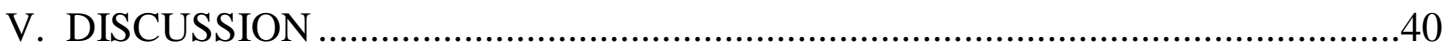

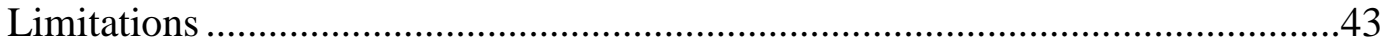

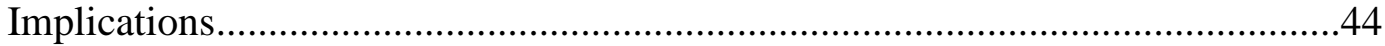

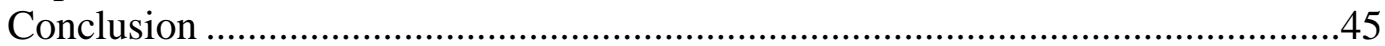

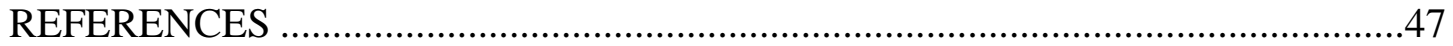

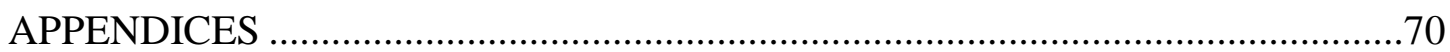

Appendix A: Institutional Review Board Approval Letter..................................71

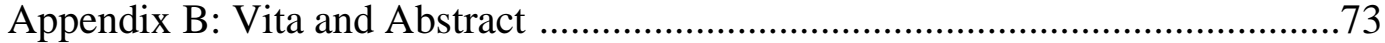




\section{LIST OF TABLES}

Table

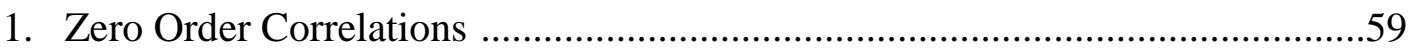

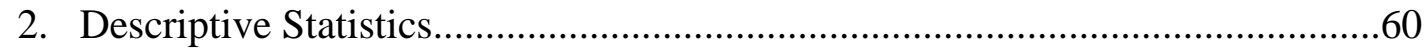

3. Co-residency in Young Adulthood and Adulthood, by gender ........................61

4. Co-residency in Young Adulthood and Adulthood, by race .............................62

5. Co-residency in Young Adulthood and Adulthood, by age .............................63

6. Co-residency in Young Adulthood and Adulthood, by race and gender........64

7. Predictors for Young Adulthood Outcomes for males.....................65

8. Predictors for Young Adulthood Outcomes for females ...............................66

9. Predictors for Male Co-residence in Young Adulthood and Adulthood ............67

10. Predictors for Female Co-residence in Young Adulthood and Adulthood.........68 


\section{LIST OF FIGURES}

Figure

Page

1. Hypothesized Model ............................................................................69 


\section{CHAPTER I}

\section{INTRODUCTION}

There has been a steady increase in the number of young adults who are remaining at home longer than in the last few decades (Settersten, Furstenberg \& Rumbaut, 2005). Currently in the United States roughly one third of young adults (early 20’s) are living at home with their parents (Litchter \& Qian, 2004; U.S. Census, 2004; Ward \& Spitze, 2007). According to 2001 Survey of Income and Program Participation, $19 \%$ of males ages $25-29$ and $13.5 \%$ of females ages $25-29$ are co-residing with parents. The transition to adulthood has been defined as: being independent, both psychologically and financially, and being able to accept responsibility for ones' behaviors (Arnett, 2001; Kins \& Beyers 2010; Nelson \& Barry, 2005; Sassler, Ciambrone, \& Benway, 2008). This definition incorporates the important role autonomy plays in achieving adulthood and the ability to become self-sufficient.

Research has shown that co-residing with parent(s) may be extending past early twenties and into early thirties; which warrants further research into understanding this prolonged transition. This study involves individuals who never left home and those who boomerang. This study provides more in depth insight into what variables are interfering with the transition to adulthood. 
According to Kins and Beyers (2010), economic and cultural changes throughout the United States have shifted the "norm" of children living on their own and taking on adult like responsibilities, such as, being self-sufficient. The current study examines young adults and adults between the ages of 18-33, a sample that has not yet been examined, specifically in the United States, in regards to living at home with parents.

Co-residence encompasses both adults who have never left the parental home as well as those individuals who leave the nest for a short period of time and then returned home (Beaupre, Turcotte, \& Milan, 2006; Furman, 2005; Mitchell, 1998). Boomerang refers to an individual who leaves the parental home for a short period of time and returns back home to live. Ward and Sptize (2007) found that young adult children who boomerang have more negative parent-child relationships than those who never leave the parental nest. The current study defines co-residence as both those who boomerang and never leave the parental nest.

Current literature is beginning to differentiate between early and late co-residents. Mitchell, Wister, and Burch (2002) defined young adults, ages 25-34, who live at home, as "mature co-residents"; whereas Cote and Allahar (1994) referred to this particular generation as the "generation at home". Although co-residency has shown to decline with age, this is not always the case. In the last decade there has been a steady increase in co-residency in Canadian young adults over the age of 25 (Boyd \& Norris, 1999). However, current co-residency literature has tended to focus on adults in their early twenties, the current study examines this particular generation, not only in their early twenties, but also in their late twenties, early thirties, a sample that has yet to be 
examined. These mixed findings suggest that there may not be a common trend for coresidency; therefore future research needs to further investigate these associations.

Researchers have suggested that this new trend could be due to several sociocultural factors, such as: completion of higher education (Mitchell, Wister, \& Gee, 2004), lack of job opportunities and income status (Mitchell, 2006), lack of psychological and material resources (Bynner, 2000), certain personality traits, and immediate family structure (Cooney \& Mortimer, 1999; Seiffge-Krenke, 2006), and cultural beliefs.

Although research has been able to show correlations between psychological and material resources, little research has examined the correlations between certain life events in adolescence and their association to living at home. The specific life events that the current study will examine are known as "precocious life events" (Wickrama, Merten \& Elder, 2005; Merten \& Henry, 2011), or non-normative early life events. Precocious life events are certain life events that throw adolescents into adulthood before they are developmentally ready. This phenomenon is also referred to as "rush to adulthood" (Wickrama et al., 2005). Precocious life events include early sexual intercourse, adolescent pregnancy, high school drop-out, early marriage, full time employment and cohabitation. Research suggests that these precocious life events tend to be more stressful because they occur too early and out of sequence (Wickrama et al., 2005). Research also suggests that precocious life events tend to be associated with poor mental and physical health well-being (Ge, Conger, \& Elder, 2001; Wickrama, Conger, Wallace, \& Elder, 2003; Wickrama et al., 2005). Individuals who experience precocious life events are at a higher risk for social, educational, and economic risks (Merten \& Henry, 2011). Individuals who experience precocious life events are likely to experience high 
levels of stress due to their lack of developmental readiness and maturity to handle these events which has shown to negatively affect an individual's health.

Precocious life events have found to be associated with a range of adverse family conditions (Wickrama et al., 2005; Merten \& Henry, 2011). Individuals who experience non-normative life events are more likely to come from families living in poverty, disrupted family structures, lack resources, and experience poor parent-adolescent relationships (Uhlenberg \& Mueller, 2003). Although the research has focused on the negative outcomes related to these rush to adulthood events, little research has examined the long range outcomes of these events. The current study examines the relationships between precocious life events, young adult status attainment, depressive symptoms and relationship quality with parents and adult co-residency with parents. This study advances research about the adverse effects of precocious life events by providing a more in-depth look at the long range impact of these events, specifically linking these events to co-residency in adulthood. Whereas, past research has found linkages between young adulthood life events and co-residency, research has yet to examine the adolescent life events and co-residency in middle adulthood.

\section{Problem Statement}

Research shows that teenage pregnancy, high school dropout, adolescent marriage, full time adolescent employment, and early home leaving contain a wide range of negative consequences for adolescents. Research has shown the negative long term outcomes of individuals who participate in these non-normative life events, such as poor mental and physical health, lack of resources (i.e. educational, financial, and social support) and unstable family environments. However, a gap exists in the research 
between the associations of "rush to adulthood" events and an adult's decision to remain at home with their parents, or return home after a period of time away. The current study will identify the pathways that lead an individual to co-reside with their parents in young adulthood and adulthood. This study will take a longitudinal approach to examining the multiple pathways between precocious life events and adults' residential decisions.

\section{Purpose of the Study}

This study utilizes a longitudinal design to examine the relationship between early life events (precocious) and residential status in adulthood, whereas most other studies have only used a cross-sectional research design to study these associations. This study will contribute new and useful information regarding the long term effects of individuals who experience early, non-normative life events. As well, it adds to the growing research on the rapidly growing phenomenon of adult children's co-residency with parents and provides new information as to why some individuals co-reside during adulthood. The longitudinal approach enhances research by establishing new pathways to adult residential status, as well; it examines the long term effects of precocious life events. It is important to examine this issue longitudinally to determine if changes in adolescent will lead to certain outcomes in young adulthood. Very little research has focused on developing predictor variables to determine which individuals will co-reside with their parents in adulthood. This research is designed to fill the current gap in the co-residency literature. This can be seen in the hypothesized model.

\section{Insert Figure 1 Here}




\section{CHAPTER II}

\section{REVIEW OF LITERATURE}

\section{Theoretical Framework}

The life course perspective emphasizes the importance of timing and sequencing of life events (Elder, 1985, 1992, 1994, 1998). Life course perspective offers a multilevel approach to understanding generational phenomena (Elder, 1994). One of the key concepts in life course perspective is the significance of timing of birth cohorts and how phenomena arise during generations. Early work in the life course perspective's early involved the generation of the Great Depression and how that time period significantly impacted childhood experiences and the pathways that arose from those experiences. This key principle emphasizes the significance that historical time and place have on generations and how those historical situations and life events have lasting effects across the life course.

Life course perspective incorporates three key mechanisms that impact developmental pathways; these mechanisms are, "issues of timing, linked lives and human agency" (Elder, 1994, p. 5). Social timing is defined as the duration, sequence of roles and expectations of the particular age (Elder, 1994). Elder (1998) stated, 
"the timing in lives states that the developmental impact of a succession of life transitions or events is contingent on when they occur in a person's life" (p. 3). Elder emphasized the importance of when the event occurs and how the timing of the event can significantly impact other transitions. This concept incorporates the idea of "goodness of fit". Marrying or having a child during adolescence are both events that are considered to be poor "fits", or ill-timed events because these events are not common expectations for this particular age period. This perspective often also uses the term "age norm" to distinguish which certain situations are more acceptable at certain ages (Settersten, 2004). Ill-timed events have shown to lead to accumulation of disadvantages (Elder 1994, 1998). For example, when an adolescent becomes a parent, they are less to likely finish high school, forced to take a low paying job and therefore end up living a poor quality of life for themselves and their child. Therefore, the timing of events is critical to the developmental stage of the individual; they need to be able to adequately meet the expectations for that transition.

The life course perspective emphasizes the critical nature of linked lives. Elder (1994) suggests how social humans are and how critical a role those social relationships play in life course perspective trajectories. Elder (1998) defined linked lives as "lives that are lived interdependently, and social and historical influence are expressed through this network of shared relationships" (p. 4). Life course perspective suggests that each decision an individual makes impacts those individuals around them. For example, "failed marriages and careers frequently lead adult sons and daughters back to the parental household and have profound implications for the parents' life plans on their later years" (Elder, 1985, p. 40). Research has shown that there is a rise in the number of 
adults who return home to the parental nest for a period of time, either due continuation of education, inability to find employment and/or to become self-sufficient (Mitchell, 2006; Mitchell et al., 2002). According to the concept of linked lives this suggests that these situations not only impact the adult but the parents they live with. However, the current study hypothesizes that there are earlier adverse events that occur that impact these decisions to co-reside with parents during adulthood.

The last key principle in life course perspective is human agency. Elder (1998) defines human agency as "individuals who construct their own life course perspective through the choices and actions they take within the opportunities and constraints of history and social circumstances" (p. 4). This concept emphasizes the personal choice an individual must make to develop their own life course. Although the life course perspective is shaped by the historical time the individual is living in and the social relationships they carry, the individual still has the power to create the life course perspective they want.

The life course perspective emphasizes the critical implications that early life choices have on future pathways (Elder, 1994). These particular transitions tend to have lasting effects on developmental pathways and significantly impact the life course perspective direction of an individual. The current study focuses on the significant impact that precocious life events have on the developmental pathway of an individual. Precocious events are often referred to as "rush to adulthood" events because they occur before the adolescent is psychologically mature to handle these adult responsibilities (Wickrama et al., 2005). Researchers suggest that these precocious life events put adolescents at an increase risk for negative consequences (Cooney \& Mortimer, 1999; 
Figueiredo, Bifulco, Pacheco, Costa, \& Magarinho, 2006; Gillmore, Lewis, Lohr, Spencer, \& White, 1997; Lee, Harris, \& Gordon-Larsen, 2009; Mollborn, 2007;

Wickrama, \& Merten, 2005; Woodward, Fergusson \& Horwood, 2001), such as poor physical and mental health, low educational attainment (Chen \& Kaplan, 1999) and unemployment. There is a lack of research on the associations between these precocious life events and adults who co-reside at home with their parents. According to the life course perspective, rushing to adulthood by consuming these adult responsibilities such as parenthood and marriage would negatively affect an individual's psychological maturity.

The life course perspective suggests that adolescence is a period of identity formation and developing emotional independence; it is not until late adolescence and early adulthood that individuals develop financial independence and the ability to become self-sufficient (Cobb, 2007). For this particular study, the period of adolescence is defined as ages 12-19, young adulthood as ages 18-26 and adulthood as ages 24-33.

It is important to examine the developmental differences between young adults, early twenties and adults, late twenties early thirties. Although prior research has examine the different developmental tasks that occur during these age periods, it's important to study the developmental tasks of adulthood through the lens of co-residency, which very little research has done. During young adulthood, it is culturally acceptable to be living with parents because an individual may be finishing school or in the process of finding stable employment, however, the cultural expectation, in the United States, for an individual in their late twenties, early thirties is to have stable employment, financially support themselves and not be living with their parents, therefore, what are the 
mechanisms that lead an individual to either return home, or never leave the parental nest? This study will provide some insight into this phenomenon.

The period of adolescence provides adolescents with a time to be experimental and develop a sense of who they are and what they want. Also, adolescence can provide these individuals with a smooth transition into adulthood and the capacity to handle the responsibilities of adulthood. In addition, life course perspective suggests that during this time period, adolescents are developing both biologically and psychological although psychological maturity does not occur until early adulthood. Therefore, adolescents who deviate from the norm and become "adults" before they are developmentally ready are more likely to experience negative psychological and social consequences when compared to adolescents who do not deviate from the normal expectations of adolescence.

Adolescence is time period that allows an individual to develop their own identity, most importantly; it allows an individual to develop the autonomy they need to achieve adulthood, therefore, without this developmental time period, an individual may not be able to develop the autonomy they need in adulthood, which might be one of the mechanisms hindering their development and one of the reasons they are not able to become self-sufficient, however, there may be other mechanisms at work to hinder this transition, such as identity development which will be discussed later on. The current study proposes that adolescents who consume adult-like responsibilities will be less likely to successfully accomplish the developmental tasks of adolescence which would extend their period of adolescence thinking. This would make them less likely to become 
financially independent and self-sufficient and more likely to remain at home with parents throughout adulthood.

The life course perspective emphasizes the importance of timing and individual development (Mitchell et al., 2004), where earlier events in one's life affect later events life. One example is an adolescent parent. Adolescents who live in poverty are at a higher risk for teenage pregnancy (Hobcraft \& Kiernan, 2001), a lifetime of poverty (Mollborn, 2007), high school drop-out, young adulthood unemployment (Alexander, 2001), and experience more conflictual family dynamics (Mallett \& Rosenthal, 2009). Elder (1994) suggests that these off time events are not isolated events, but a process of events. Speeding up the life course perspective trajectory or skipping important developmental stages are more likely to be associated with negative outcomes. These individuals are likely to experience a more adverse life course perspective trajectory due to their rush to adulthood, when compared to adolescents who experiences a more normative trajectory. However, this is not always the case; research has shown that adolescents who experience precocious life events are more likely to experience more negative outcomes than a "normative" adolescents.

Research has shown that individuals who are experiencing adverse situations are more likely to engage in precocious events (Wickrama et al., 2005), which could negatively impact their overall well-being. The life course perspective suggests that events occur in a sequence, and when events occur out of sequence there are often times negative consequences associated for these out of sequence life events. For example, Figueiredo and colleagues (2006) found that adolescent parenthood has been associated with low educational attainment, unemployment and poverty. There appear to be several 
negative consequences that follow these off timing events; however, if an individual has reliable access to several material resources, they are less likely to suffer from the negative consequences that occur with these off timing events.

The life course perspective suggests the importance of completing each developmental task on time. Havighurst (1948) proposed that in order for an individual to experience positive well- being they must successfully complete each developmental task in the order that society suggests is normal. According to this assumption, an adolescent who has a child is not going to be able to successfully "accomplish" the developmental tasks of adolescence because of the birth of the child. Therefore, compared to an adolescent that does not have a child, their overall well- being would be much higher, and would be less likely to live at home during adulthood because they were able to accomplish the developmental tasks of adolescence.

This perspective suggests that when developmental tasks are not met, the individual is likely to experience negative outcomes. For example, Mitchell (1998) found that "off time" transitions (i.e. delayed nest leaving and/or boomerang) have been found to "violate parental expectations", which has been shown to negatively affect parental well-being, and has also shown to effect the parent-child relationship quality as well as the marital relationship (p. 24).

Heinicke (2002) suggests that certain life transitions and events evoke higher levels of stress because they change individuals' roles and create higher levels of role stress. Role stress plays in important role in individual and family formation. The individuals' and families' inability to accept the precocious life event inherently create stress for the individual and the family. The stress is initially created because of the 
timing of the life event, a life event which is neither planned nor expected, because it is abnormal in adolescence. The role of these precocious life events can evoke a large amount of stress for the individual and their family. Because of the lack of developmental maturity during adolescence, they are more likely not to have the psychological and material resources to manage the event, which would hinder their psychological development, which may increase the likelihood of co-residing during adulthood. The current study will assess these associations.

As mentioned in earlier, identity may also play a role in predicting young adults who live at home. Mead's identity theory suggests that the self reflects society, and that identity standards are set by the culture that an individual is living in (Stryker \& Burke, 2000). It there appears, that if a sizeable percentage of Americans co-residing with their parents in their late twenties, early thirties, this may not necessary just reflect the individual, but the United States culture. The culture may be shifting towards cultural norms that expect the transition to adulthood to last into late twenties and early thirties. Co-residency may not be a cultural norm, but norms of certain racial groups or social classes. As previous literature has suggested, minority groups are more likely to coreside than Whites (Aquilino, 1996; Mitchell et al., 2004) and certain social classes may be more inclined to co-reside than others.

\section{Literature Review}

\section{Precocious Life Events and Co-residency}

Wickrama et al. (2005) looked at the associations between precocious life events and community and family disadvantages and adolescent depressive symptoms. They found that adolescents who reported community disadvantaged and adverse family 
conditions were at a higher risk for precocious life events in adolescent and adolescent depressive symptoms. Merten and Henry (2011) found that adolescent females who reported more positive relationships with their mothers were less likely to report precocious events in adolescents and were less likely to experience depressive symptoms in adolescents, when compared to adolescents' females who reported more negative mother-daughter relationship quality.

Very little to no research has looked at the direct links between precocious life events and co-residency. This study hopes to fill this gap in the co-residency literature by looking at this association and developing a developmental pathway for non-normative life events in adulthood.

\section{Precocious Life Events and Well-being}

Research has found that that precocious life events tend to be associated with poor mental and physical health well-being (Figueiredo et al., 2006; Ge et al., 2001; Hammond, 2002; Irvine, Bradley, Cupples, \& Boohan, 1997; Kalil \& Kunz, 2002; Kaplan, 1996; Karmakar \& Breslin, 2008; Merten \& Henry, 2011; Mollborn \& Moringstar, 2009; Nelson \& Barry, 2005; Nesman, 2007; Schulz, Isreal, Zenk Parker, Lichtenstein, Shellman-Weir, Klem, 2006; Shaw, Lawlor, \& Najman, 2006; Topitzes, Godes, Mersky, Ceglarek, \& Reynolds, 2009;Wickrama et al., 2003; Wickrama et al., 2005). Individuals who experience precocious life events are at an increased risk to experience high levels of stress due to their lack of developmental readiness and maturity to handle these events, which has shown to negatively affect an individual's health.

This "rush to adulthood" has been shown to increase the likelihood of adolescent and adulthood depression (Figueiredo et al., 2006; Kalil \& Kunz, 2002; Mollborn, 2009; 
Prater, 1995). Adolescent mothers are susceptible to depression due to hormonal imbalances (Danziger, Corcoran, Danziger, Heflin, Kalil, Levine et al., 2000), lack of material and psychological resources (Kalil \& Kunz, 2002; Mollborn, 2009; Prater, 1995), and poor social support (Schulz et al., 2006). It has also been shown that adolescent parents are at a higher risk for depressive symptoms because of their lack of opportunities later in life (Webbink, Martin, \& Visscher, 2008). These opportunities include educational attainment and job opportunity. Adolescent parents tend to live a life of poverty which has shown to be positively linked to poor mental health and high rates of depression.

Due to the lack of material and psychological resources accessible to adolescent parents, it is more common for these adolescents to experience poor mental health. Research has shown a correlation between mental and physical health, and often times both are interdependent. Research suggests an association between teenage pregnancy and physical health. Adolescent parents are more likely to be economically disadvantaged than adolescents without children and are less likely to have access to good health care. These adolescent parents are at an increased risk to smoke and be highly involved with alcohol (Shaw, Lawlo \& Najman, 2006). Webbink et al., (2008) found that adolescent mothers are also more likely to be obese when compared to adolescent non-mothers.

Hammond (2002) conducted a meta-analysis that examined the correlations between education and health. The study found that low education attainment is associated with higher levels of depression and anxiety, higher number of sick days reported, higher likelihood for attempt suicide, and Alzheimer's disease. Hammond 
suggests that there is a strong correlation between education and healthy behaviors. Individuals who are more educated are more likely to adopt healthier behaviors, such as eating healthier, exercising more often, less likely to smoke and be involved in illegal drug usage, use seat belts, practice safe sex, and seek medical attention when warranted as compared to less educated individuals.

Research has a shown a strong correlation between high school drop-out rates and physical and emotional support in the home and the school. Storm and Boster (2007) state that the importance of strong communication between adult and adolescent to facilitate academic achievement. They suggest how the flow of positive communication is crucial for high school completion. Often adolescents who end up dropping out of school lack positive communication in regards to school, lack motivation and often times are stuck in a vicious cycle of generational poverty. Studies have shown how living in poverty negatively impacts an individual's academic career and leaves them with poor educational and financial opportunities.

Minimal research has examined the correlations between educational attainment and adult mental health. Individuals who achieve low educational attainment are more likely to experience depressive symptoms (Koster, Bosma, Kempen, Penninx, Beekman, Deeg, et al., 2006; Masten, Rosiman, Long, Burt, Obradovic, Roberts, et al., 2005). Topitzes et al., (2009) conducted a longitudinal study that found that the individuals who complete high school are less likely to suffer from depression as adults. Studies have also shown gender differences in the prevalence of depression and high school drop-outs, with females more likely to suffer from depression due to high school drop-out than males (Fletcher, 2008). 
Low educational attainment and high school dropout rates have also been associated with low levels of social support. A majority of adolescents who report dropping out of high school also report poor relationships with school. In addition, these adolescents often lack a supportive relationship from their parents. Leadbeater and Way (2001) suggest a positive association between low supportive families and high levels of physical and psychosocial issues.

Kalil and Ziol-Guest (2008) found that adolescent mothers who perceived a supportive relationship with their school teachers were more likely to experience higher levels of academic motivation, which increased the likelihood of continuing their high school education. They go on to state that these caring relationships that the teachers develop with these students help "alleviate stress and allow them to respond more effectively to academic challenges and opportunities" (Kali \& Ziol-Guest, 2008, p. 542), which increases the likelihood of further their educational goals.

\section{Precocious Life Events and Young Adult Status Attainment}

Research has shown that adolescents who report precocious life events are more likely to have low educational attainment (Chen \& Kaplan, 1999); become unemployed in young adulthood and live in poverty (Alexander, 2001; Oreopoulos, 2007). Cherry, Dillon, and Rug (2001) found that $75 \%$ of teenage parents grow up in poverty. Adolescent parents are more likely to come from low a socioeconomic background, which may hinder the amount of material resources that are available to them. Most often these families lack material resources, such as income, adequate housing, and childcare (Mollborn, 2007). Adolescent parents who lack material resources are also more likely to drop-out of high school because they cannot find affordable childcare. 
Mollborn (2007) suggests that adolescent parents experience a low level of educational attainment because of their lack of resources and their immediate need for employment rather than education.

Bradley and colleagues (2002) conducted a case study and found a deprivation association between teenage motherhood, poor educational achievement, and unemployment (Bradley, Cuppres \& Irvine, 2002). Adolescent parents are more likely to experience unemployment because of their low educational achievement, which further deprives these adolescents of the material resources they need to care for themselves and for their children. Kiernan (1997) conducted a longitudinal study that found that adolescent parents are less goal-driven than adolescents without children. This personality characteristic could be associated with the idea that these adolescent parents are tied down to these adult responsibilities too early. This forces them to adopt an adult like maturity before they are psychological ready.

In $2007,8.7 \%$ of the students between the ages of 16-24 enrolled in high school dropped out, which amounts to 3.3 million students not completing high school (U. S. Department of Education, 2009). Research has shown that dropping out of high school leads to a series of negative consequences such as, low paying job (Angrist, \& Krueger,1991), more likely to be unemployed (U. S. Census Bureau, 1999), lack other material resources (Campbell \& Duffy, 1998; Kalil \& Ziol-Guest, 2008; Oreopoulos, 2007). Also, males are more likely than females to drop-out out of high school. Research also has shown that ethnicity is a high risk factor for high school dropout. Of those who do drop-out 21.4\% are Hispanic, 8.4\% African American, 6\% Asian and 5.3\% are white (U. S. Department of Education, 2009). 
Research has suggested a positive correlation between adult like employment during early and mid adolescent and high school dropout. Entwisle and colleagues (2005) found that if employed in adult like work before age 16 there is a higher risk of high school drop-out. But if employed at or after age 16, there is less of a chance that the adolescent will drop-out of school (Entwisle, Alexander, \& Olson, 2005). A possible explanation for this correlation could be due to the associations between a family economic status and need for income. In some families it is expected that an adolescent obtain employment to help the family with their financial burden. However, when this is the case with a family, the family tends to devalue the importance of education, which has shown to increase the likelihood for dropping out of high school and increase the likelihood of obtaining a low paying job in adulthood.

Early marriage (marriage during adolescence) has shown to lead to lower psychological and material resources because they have rushed into a developmental stage where they are not emotionally or financially ready; this can negatively impacts their overall well-being. Goldsceider and Goldscheider (1998) found that adolescents who come from economically advantaged families with a high pool of resources are less likely to leave the parental home, and deliberately avoid marriage. Individuals who come from a high socioeconomic background are less likely to leave the parental home and engage in early marriage, with the fear of loosing access to parental resources. These individuals tend to have a greater parent-adolescent relationship, which is one of the key factors as to why they do not feel the need to leave the parental nest, or why they feel so comfortable returning to the parental nest at any given time. 


\section{Precocious Life Events and Parental Relationship Quality}

Past research has found an association between precocious life events and parentchild relationship quality. Research has suggested that adolescents who experience a high level of family discord are more likely to become pregnant during adolescence (Hardy, Astone, Brookes-Gunn, Shaoro, \& Miller, 1998). However, adolescents who experience more family discord and poor relationship quality with parents are more likely to leave the family home during adolescence (Chen \& Kaplan, 1999; Goldscheider \& Goldscheider, 1998). Adolescents who experience non-normative life events are more likely to come from disrupted family structures, perceived poor parent-adolescent relationship quality (Merten \& Henry, 2011; Uhlenberg \& Mueller, 2003) and experience conflictual family dynamics (Mallett \& Rosenthal, 2009).

Several studies have emphasized the importance of family structure and family relationships to individuals who leave the parental home early. Research has found that early home leavers often come from non-intact families (Chen \& Kaplan, 1999; Tang, 1997), disrupted families (Goldscheider \& Goldscheider, 1998), and families with high levels of conflict and stress (Mallett \& Rosenthal, 2009). However, there has been conflicting research on whether family structure or family relationships are more influential in an individual's decision to leave the parental home.

Goldscheider and Goldscheider (1998) propose that a healthy and secure family environment is a core deciding factor in successfully launching children into adulthood. They suggest these types of family environments allow the children to accomplish developmental tasks on time and allow them to develop financial and emotional independence. They also found that adults who come from a "non-traditional" family 
structure, such as blended families or single parent households, are more likely to experience early home leaving and more difficult transitions into adulthood, most likely due to the amount of conflict that exists in the household. Chen and Kaplan (1999) found that adolescent residing in more traditional family household are less likely to experience precocious life events. Merten and Henry (2011) found that a positive mother-daughter relationship decreases the risk against precocious life events and depressive symptoms in adolescence. The current study proposes that individuals who come from a family that originates from poor family relationship quality are less likely to remain at home.

\section{Depressive Symptoms and Co-Residency}

Very little to no research has examined the link between depressive symptoms in young adulthood and co-residency with parent(s) in adulthood. However, past research has examined the associations between precocious events and depressive symptoms, the research has yet to further their link and examine these associations as developmental pathways to co-residence in adulthood. The current study proposes that individuals who report more depressive symptoms are more likely to co-residence with their parent(s) during adulthood when compared to those individuals who report low or no depressive symptoms.

\section{Young Adult Status Attainment and Co-Residency}

Researchers have found a strong correlation between co-residence individuals and material resources (Avery, Goldscheider, Speare, 1992; Mitchell, 1998; 2006; Mitchell et al., 2006). Many young adult individuals who move back into their parent's house because of lack of financial resources to live on their own. Individuals who have low paying jobs have a higher likelihood of returning home to the parent nest because of their 
lack of ability to financial support themselves (Mitchell et al., 2006). Individuals who come from economically advantaged families are more likely to boomerang back to their parents' house after leaving because of their access to their parents' tangible resources and the ability to save their own personal resources. However, this association is contingent on the type of parental relationship these adults have with their parents. Individuals with a strong relationship are more likely to return home then those who have a poor relationship (Mitchell et al., 2006).

\section{Parental Relationship Quality and Co-Residency}

Aquilino (1996) and Mitchell and colleagues (2004) found that individuals who live in non-intact families are less likely to return home to live with their parents during adulthood. One of the main reasons for this association is non-intact families have shown to express higher levels of family conflict which makes the living environment less desirable and decreases the likelihood for an individual to move back into the family nest during adulthood. Mitchell and colleagues (2004) found that adolescents who report more positive relationships with their families are more likely to co-reside with their parents during adulthood when compared to adolescents who report more negative parent relationships.

\section{Family Economic Hardship and Co-Residency}

Families who live in poverty are at an increased risk for co-residency in adulthood. However, there has been mixed research regarding the association between family economic hardship and co-residency. Some research has found that economically disadvantaged individuals are more likely to leave the parental home earlier than economically advantaged individuals because of the lack of resources available to them. 
The idea behind this notion is that economically disadvantaged adolescents believe they will be able to obtain more resources if they are on their own. However, they are more likely to obtain low paying jobs that lead to lower acquisition of tangible resources. Other research has suggested that economically disadvantaged individuals will remain in the home longer because of the scarce resources and the dependency on the family to provide as a whole. Nonetheless, this is usually dependent on the quality of the parentadolescent relationship, with a more positive relationship being linked to co-residency in adulthood.

Research has shown that parental education to be associated with co-residence in adulthood. Goldscheider and Goldscheider (1999) and Mitchell and colleagues (2000) found that more highly educated parents tend to have children with more education. Individuals with parents with low educational attainment are likely to have low educational attainment when compared to families with high educational attainment. Individuals with low educational attainment are more likely to have low paying jobs and force adults to co-reside with parents so that they can share resources. However, young adults who come from economically advantaged families are more likely to return home because of their relationship with their parents and the accessibility to a large amount of material resources and if their parents were financially supporting them (De Vanzo \& Goldscheider, 1990). However, Garasky (2002) found that parental wealth increased the likelihood for leaving the parental home and decrease the likelihood for boomerang because the family had access to money, privacy and the shift of wealth from the parents to the child. 


\section{Parental Marital Stability and Co-Residency}

Research has shown a negative correlation for parental marital dissolution and adulthood co-residence (Aquilino, 1996). Mitchell and colleagues (1989) found that parental remarriage, step-parenting and single parenting were associated with children leaving the parental home at an earlier time and not residing with at home with parents during adulthood. However, past research has shown that individuals who derive from a more traditional structure, parental marriage with biological children, and these individuals are more likely to co-reside with parents during adulthood. This association warrants further investigation.

\section{Gender and Co-Residency}

Research has shown that females are more likely to experience precocious events when compared to males (Chen \& Kaplan, 1999), which may increase the likelihood for females co-residing with parents during adulthood. However, little research has examined a direct correlation with gender and co-residency. A majority of the research has examined this phenomena contingent to other variables, such as relationship issues, depression, financial issues or other unknown issues The current study will control for this variable to assess the association between gender and co-residency.

\section{Race and Co-residency}

Some research has examined the association between race and precocious life events but little research has examined the links between race and co-residency. However, Mitchell and colleagues (2004) found that Asian families are more likely to coreside during adulthood due to cultural beliefs and expectations, such as staying at home until marriage, whereas British households are less likely to have adult children living in 
the home because of the more autonomous cultural expectations in these households. Aquilino (1996) found that African American and Hispanic families are more likely than Whites to have adults co-residing with parents during adulthood. However, this finding was associated to cultural beliefs and the importance of multi-generational households. However, a gap exists in co-residency literature in assessing a direct correlation between race and co-residency. This study will look at White, African American, Hispanic and Asian adults and their likelihood to co-reside with their parents during young adulthood and adulthood.

\section{The Current Study}

The current study examines the different pathways an individual may take that to remain living with their parents or returning to live with their parents in adulthood. Specifically this study will examine how precocious life events in adolescence alter the pathway an individual takes, and how often these pathways lead co-residency with parents in adulthood. The following specific hypotheses will be examined:

1. An increase in the number of precocious life events in adolescence will increase the likelihood of co-residence with parents in adulthood.

2. A greater number of precocious life events in adolescence will be positively associated with depressive symptoms in young adulthood.

3. A greater number of precocious life events in adolescence will be negatively associated with lower young adult status attainment.

4. A greater number of precocious life events in adolescence will be negatively associated with relationship quality with parents in young adulthood. 
5. Young adult depressive symptoms will increase the likelihood of co-residence with parents in adulthood.

6. Greater young adult status attainment will decrease the likelihood of co-residence with parents in adulthood.

7. Greater relationship quality with parents in young adulthood will increase the likelihood of co-residence with parents in adulthood.

8. Precocious events in adolescence will be related to co-residence with parents in adulthood through depressive symptoms, young adult status attainment and/or relationship quality with parents in young adulthood.

9. Whites will be less likely than other racial/ethnic groups to co-reside with their parents during adulthood. 


\section{CHAPTER III}

\section{METHODOLOGY}

\section{Sample}

Data came from Wave 1 (1995), Wave 2 (1996), Wave 3 (2001), and Wave 4 (2008) of the National Longitudinal Study of Adolescent Health (Add Health), a longitudinal study of adolescents addressing their health behaviors and lifestyle is used for this study. The primary sampling frame included high schools in the United States that had an $11^{\text {th }}$ grade and at least 30 students enrolled in the school. A systematic random sample of 80 high schools were selected from this complex sampling frame. The sample was divided by urbanicity, school type, region, ethnic mix, and size. The final Add Health sample included 134 schools. A total of 20,745 adolescent were included in Wave 1 (1995). In addition to adolescent self-report data, a total of 17,000 parents were interviewed in order to gain additional family and adolescent data. Schools selected for the randomized study varied in size, from 100 to 2,000 students. A school roster was used to select a group of adolescents for in home ninety minute interviews. Information regarding information about this data set is available at http://www.cpc.unc.edu/projects/adhealth. The present study however uses wave 2 (adolescents ranged from 12 to 19), wave 3 (young adults ranged from 18-26) and wave 4 (adults ranging from 24-33). 
Wave 1 data was only used to assess family economic hardship of adolescents as Wave 2 data did not provide this information during adolescence. The sample consists of 10,076 individuals who provided complete data during Wave 2, 3, and 4. These three waves of data were used in this study in order to have a different developmental period represented (adolescence, young adulthood, adulthood) to examine change in various outcomes. The sample includes $45 \%$ male and $55 \%$ female. Regarding race/ethnicity, percentages were as follows: White 56\%, African American 21\%, Hispanic 15\%, Asian $6 \%$, and Native American $2 \%$.

\section{Measures}

Co-residence with parents. This was measured during both young adulthood (Wave 3) and adulthood (Wave 4), by asking respondents where they currently reside and household composition questions to determine their relationship with household members. Several variables were then created to determine the following: "Did respondents live at home with their parents during young adulthood?" "Did respondents live at home with their parents during adulthood?" "Did respondents live at home with their parents during both young adulthood and adulthood". Responses to these questions were $0=$ no or $1=$ yes.

Adolescent precocious life events. A composite measure of precocious life events was created by counting life events that adolescents reported during Wave 2 data collection. The precocious life events measure included the following items (1) leaving home prior to age $18,(2)$ pregnancy prior to age $16,(3)$ dropping out of high school, (4) marriage and/or cohabitation and (5) full time employment (more than 30 hours a week). The national average age of childbearing is 24.6 years of age (Matthews \& Hamilton, 
2002); national average age of home leaving was 21 years of age (Kreiter, 2003). The national average age for first marriage for men is 27.4 and 25.6 for women (Cherlin, 2010). The maximum age of respondents in Wave 2 was 19; therefore these events were assessed as precocious. The index of precocious life events ranged from 0 to 5 ; with 0 being not experienced any of these precocious life events and 5 having experienced all five of them. These five items have been used previously to measure precocious life events (Merten \& Henry, 2011; Wickrama et al., 2005).

Relationship quality with parents. This was measured by asking participants their perceptions about their relationship quality with their current residential parent or previous residential parent, if not currently living with parent(s). The following three questions were used to assess relationship quality in both young adulthood and adulthood between participants and their current or previous residential mother and father: "You enjoy doing things with him/her?" "Most of the time he/she is warm and loving toward you." These questions yielded responses ranging from $0=$ strongly disagree to $5=$ strongly agree. The third question asked, "How close do you feel to him/her? Responses ranged from $0=$ not close at all to $5=$ extremely close. Merten and Henry (2011) used a similar measure to assess parental relationship quality. This measure had a Cronbach's alpha for the relationship quality with fathers was 0.94 and 0.85 for relationship quality with mothers.

Family economic hardship. Family economic hardship was created by specific items that were reported by the parent. The economic hardship questions assessed family poverty by asking if the family (1) received food stamps, (2) received Aid to Families with Dependent Children (now TANF), or (3) was receiving welfare. Similar items have 
been used in previous studies to assess for family economic hardship (Wickrama \& Bryant, 2003). Cronbach's alpha for this 3-item measure was 0.96.

Biological parents marital status. A measure of parental marital status was created by assessing a number of household questions focused on household composition and relationships in both adolescence and young adulthood. Participants who had biological parents married living together in the same household during Wave 2 and/or Wave 3 were coded as " 1 "; otherwise $=0$.

Young adult status attainment. Young adult attainment was measured by combing five variables $(1=y e s, 0=n o)$. The items asked the participants if they (a) were either employed full time or in college full time, (b) their satisfaction with their current employment, (c) if they own their housing, (d) if they had a high school diploma or a GED, and (e) had completed an associates or bachelors degree. These items are similar to the ones used by Merten, Wickrama and Williams (2008). This index ranged from 0 to 5 , with 0 having said no to all items and a 5 indicating a yes to all 5 items.

Depressive symptoms. Depressive symptoms were measured in both Waves 2 and 3. A total of 9 items from the Center for Epidemiological Studies Depression Scale_CES-D; Radloff, 1977) were used since all 9 items were asked of respondents in both Wave 2 and Wave 3. The following sample questions were used to assess feelings of distress: During the past seven days...."you were bothered by things that usually don't bother you,", "felt depressed, tired and sad", “felt people disliked you”, “ were too tired to do things." These questions have been widely used to assess depression symptoms in other studies (Radloff, 1977; Merten et al., 2008). Responses for each item ranged from 0 (never or rarely) to 3 (most or all the time). The total range on the measure was 0 to 
27 , with higher scores indicating greater number of depressive symptoms. The Cronbach's alpha for the 9-item measure for Wave 2 and Wave 3 was 0.80 .

Race/Ethnicity. A set of four dichotomous variables were used to contrast racial/ethnic categories of African-American (1=African-Americans, $0=$ other $)$, Hispanic (1=all Hispanic minorities, $0=$ other $)$, Asian (1=Asians and Pacific Islanders, $0=$ other $)$, $1=$ Native Americans, $0=$ other) against all other ethnic groups with White (used as the reference group).

\section{Data Analysis}

\section{Descriptive Statistics}

First, zero-order correlations among all the major study variables will be examined (Table 1). Next, means, standard deviations, and ranges of all study variables will be presented in Table 2 .

\section{Linear Regression Analyses}

Linear regression analyses will be run separately for males and females in order to account for potential differences that may exist in regards to associations among study variables. The following young adult outcomes will first serve as dependent variables in

order to examine the associations between factors in adolescence as well as race/ethnicity have on young adult depressive symptoms, status attainment, and relationship quality with parents. All variables will be entered into the model simultaneously in order to see the net association between two variables.

\section{Logistic Regression Analyses}

Tables 9 and 10 will present logistic regression models that will include adolescent factors entered in Model 1 predicting the likelihood of co-residence with 
parents in both young adulthood and adulthood. Next, young adulthood variables, which include depressive symptoms, young adult status attainment, and relationship quality with parents will be added into Model 2 to determine whether these three young adulthood variables mediate the potential relationship between precocious events and adult coresidence with parents. In Model 3, race/ethnicity will be added to determine the unique effects of all variables in the model.

According to Baron and Kenny (1986), in order to establish mediation, several conditions must be met. First, it must be established that precocious life events (predictor variable) is significantly associated with co-residence with parents in adulthood (outcome variable) when young adulthood variables (mediators) depressive symptoms, young adult status attainment, and relationship quality with parents were not included in the model. Second, precocious events must be significantly associated with the mediator variables (depressive symptoms, young adult status attainment, and relationship quality with parents) and also the mediators must be significantly associated with the outcome variable, co-residence with parents in adulthood. Meeting these steps provides evidence that supports a mediating relationship. 


\section{CHAPTER IV}

\section{FINDINGS}

\section{Descriptive Statistics}

Zero-order correlations were examined on all major variables in this study (Table 1). Precocious life events was negatively correlated with co-residency with parents in Wave 3 ( $\mathrm{p}<.01)$. In addition, precocious life events were not correlated with co-residency with parents in adulthood or co-residency in both young adulthood and adulthood. Young adult status attainment was negatively correlated with precocious life events, as well as co-residency with parents in young adulthood, and adulthood $(\mathrm{p}<.01)$. Adolescent precocious life events were positively correlated with depressive symptoms in young adulthood $(\mathrm{p}<.01)$. Young adult depressive symptoms were also positively correlated with greater likelihood of co-residency with parents during both adulthood and young adulthood. Biological parents married at Wave 2 was positively correlated with biological parents married at Wave $3(\mathrm{p}<.001)$. African Americans and Hispanics reported a greater number of precocious events compared to Whites $(\mathrm{p}<.01)$. Females were less likely, than males, to co-reside with parents throughout young adulthood and adulthood $(\mathrm{p}<.01)$.

Insert Table 1

Table 2 provides the means, standard deviations and ranges for the study variables. $42 \%$ of participants reported residing with parents during young adulthood. In 
addition, $17 \%$ of participants co-residing with parents during adulthood. The percentage of participants who reported co-residency with parents in both young adulthood and adulthood was $11 \%$. The mean level of precocious life events in adolescence was 0.36 $(\mathrm{SD}=0.62)$ and range of $0.00-5.00$. The mean level of young adult status attainment is $2.75(\mathrm{SD}=0.80)$ and a range of 1.00-5.00. The mean level of depressive symptoms in young adulthood is $4.68(\mathrm{SD}=4.09)$ and adulthood is $5.29(\mathrm{SD}=4.11) .55 \%$ of the adults interviewed were female, 21\%, African American, 15\% Hispanic and 6\% Asian. The average age of participants at Wave 3 (young adulthood) was 21.60 years and 28.14 years at Wave 4 (adulthood).

Insert Table 2

Table 3 shows the percentages of females and males by co-residency status during young adulthood and adulthood. A total of $48 \%$ of males reported never co-residing with parents in either young adulthood or adulthood, compared to $58 \%$ of females. Coresidents with parents in both young adulthood and adulthood occurred among $14 \%$ of males and $10 \%$ of females. $5 \%$ of adults reported living with parents during adulthood only.

Insert Table 3

Table 4 provides the percentages of residential status in young adulthood and adulthood, by race. In adulthood, 8\% Asian, 5\% Hispanic and 6\% African American 
reported living with their parents. In young adulthood and adulthood, 20\% Asian, 19\% Hispanic and 15\% African American reported co-residing.

\section{Insert Table 4}

Table 5 shows the ages of co-residers in both young adulthood and adulthood. During young adulthood, a higher percentage of young adults are co-residing with parents, whereas during adulthood, the numbers of co-residers appears to drop by approximately half. At age 32, 21\% reported living with their parents, about the same percentage that reported living with their parents at age 24 in Wave 4.

\section{Insert Table 5}

Table 6 shows the percentage of co-residents in young adulthood, adulthood and both young adulthood and adulthood, by race and sex. Twenty two percent of Asian males reported co-residency in young adulthood and adulthood, followed closely by Hispanics males with 21\% and African American males with 19\%. In contrast, White females reported the lowest percentage of co-residing in young adulthood.

Insert Table 6

\section{Regression Analyses}

Table 7 presents the unstandardized regression coefficients for the independent variables on young adult outcomes for males. Results indicate an increase in young 
adult status attainment is associated with a lower number of depressive symptoms in young adulthood $(\mathrm{B}=-0.51, \mathrm{p}<.001)$. Relationship quality with father in young adulthood was significantly associated with a decrease in depressive symptoms reported in young adulthood $(\mathrm{B}=-0.22, \mathrm{p}<.001)$. In contrast, relationship quality with mother was not significantly associated with young adult depressive symptoms. African Americans had a greater number of depressive symptoms in young adulthood compared to Whites $(\mathrm{B}=0.41, \mathrm{p}<.05)$. All of these factors explained $16 \%$ of the variation in depressive symptoms during young adulthood.

The greater number of precocious life events in during adolescence was associated with lower young adult status attainment $(B=-0.16, p<.001)$. African American and Hispanic males had lower young adult status attainment than White males $(\mathrm{B}=-0.13, \mathrm{p}<0.01$ and $\mathrm{B}=-0.17, \mathrm{p}<0.01)$. However, the results revealed that for males, the lower the relationship quality with mother, the greater the young adult status attainment was in Wave $3(\mathrm{~B}=-0.03, \mathrm{P}<.001)$.

\section{Insert Table 7}

Table 8 presents the unstandardized regression coefficients for independent variables on young adult outcomes for females. Similar to males, the greater number of precocious events in adolescence is associated with a decrease in young adult status attainment $(B=-0.20, p<.001)$. Adolescence precocious events is negatively associated with relationship quality with mother during young adulthood $(\mathrm{B}=-0.68, \mathrm{p}<.001)$. Similar to the finding with males, higher relationship quality with mother was negatively associated with young adult status attainment. Upon examining this association further it 
was found that the negative association between mother relationship quality and young adult status attainment was contingent upon whether the male lived with their parents during young adulthood, similar to finding among males. Among young adults not living with their parents, mother relationship quality was negatively associated with young adult status attainment. However, mother relationship quality in young adulthood was positively associated with greater status attainment among young adults living at home A higher young adult status attainment in young adulthood was likely to decrease the percentage of depressive symptoms in Wave 3 among females $(B=-0.69, p<.001)$. Results indicate a negative association between relationship quality with father and depressive symptoms in $(\mathrm{B}=-0.24, \mathrm{p}<.001)$. All of these factors explained $17 \%$ of the variations in depressive symptoms during young adulthood and $13 \%$ of the variations in young adult status attainment for females.

\section{Insert Table 8}

Table 9 provides logistic regression coefficients for the effects of adolescent and young adulthood factors and race/ethnicity on male co-residence in both young adulthood and adulthood. Model 1 shows that depressive symptoms in adolescence increases the likelihood of co-residency in both young adulthood and adulthood ( $\mathrm{OR}=1.06, \mathrm{p}<.001)$. Model 2 adds young adulthood factors. The results indicate that greater young adult status attainment decreases the likelihood of co-residency in adulthood $(\mathrm{OR}=0.58, \mathrm{p}<$ .001). Greater relationship quality with father decreased the likelihood of co-residing with parents, compared to males with lower relationship quality with father $(O R=0.93, p$ 
$<.01)$, whereas greater mother relationship quality increases the likelihood of co-residing by $26 \%$.

Model 3, race and ethnicity factors are added. Depressive symptoms remain significantly associated with increased likelihood of co-residing $(\mathrm{OR}=1.05, \mathrm{p}<.01)$. Greater young adult status attainment decreases the likelihood of co-residency by $42 \%$. African Americans, Hispanics and Asians are all more likely than Whites to co-reside with their parents during adulthood.

Insert Table 9

Table 10 presents the logistic regression coefficients for the effects of adolescent and young adulthood factors and race/ethnicity on female co-residence in both young adulthood and adulthood. Model 1 indicates that precocious events are not significantly related to the likelihood of co-residency in adulthood. Biological parents being married during adolescence was associated with a greater likelihood of co-residency in both young adulthood and adulthood $(\mathrm{OR}=1.64, \mathrm{p}<.001)$. Father relationship quality decreased the likelihood for co-residency in young adulthood and adulthood by 0.93 times, for females.

Model 3 adds race and ethnicity factors. Asian females are 2.18 times more likely than white females to co-reside in adulthood. African American and Hispanic females are also more likely than White females to co-reside at home during young adulthood and adulthood $(\mathrm{OR}=2.43, \mathrm{p}<.001 ; \mathrm{OR}=2.69, \mathrm{p}<.001)$. 
Insert Table 10 


\section{CHAPTER V}

\section{DISCUSSION}

The findings in this study generally support the proposed hypotheses, which examined the pathways that lead adult-children to co-reside with their parents in young adulthood and adulthood. This study found that a greater relationship quality with their mother lead to a higher likelihood of co-residing during adulthood; the finding was significant for both females and males. Previous research supports this finding, indicating the significant impact of the parent-child relationship and a child's decision to co-reside with parents during adulthood (Goldscheider \& Goldscheider; 1998; Mitchell, 2004).

Adult children are more likely to co-reside with parents when they experience a positive relationship and a welcoming environment in the home. The study found young adults whose biological parents remained married during young adulthood are 2.00 times more likely to co-reside with their parents in both young adulthood and adulthood than young adults whose biological parents are not married. This finding is consistent with previous research that suggests that intact families are more likely to co-reside than non intact families (Aquilino, 1996; Mitchell et al., 2004). These families may provide more warm and nurturing home environments which may be the reason why these adults choose to co-reside at home, which portrays a positive trait of co-residency. Individuals co-residing in young adulthood and adulthood may perceive a more positive and welcoming social support system at home and then may choose to co-reside because of those positive parental relationships. 
This study found that relationship quality was an important factor in predicting co-residency in young adult and adulthood. Greater relationship quality with fathers decreased the likelihood of co-residing with parents during adulthood. Previous research has shown that co-residency tends to strain the parent-child relationship (White \& Rogers, 1997), which may discourage individuals from ever co-residing with the fear of damaging the relationship. Future research should investigate this relationship and why this is only the case for the father- child relationship. However, the results also showed that the greater the relationship quality with mother, the greater the likelihood for coresidency in young adult and adulthood. This study speculates that this association may be linked to mother education level, where low levels in mother education is associated to low levels in child education which has shown to increase the likelihood of co-residency in adulthood (Goldscheider \& Goldscheider, 1999; Mitchell et al., 2000).

As anticipated, the findings showed that an increase in precocious life events in adolescence decreased the odds of young adult status attainment in young adulthood. Precocious events may reduce an individuals' ability to obtain full time employment, own housing, and obtain a college degree (Smits, Gaalen, \& Mulder, 2010; Mollborn, 2007; Wickrama et el., 2005). Precocious life events can hinder an individual's access to available resources in young adulthood. However, relationship quality did show to have a significant effect on young adult status attainment; with a greater father relationship quality increases status attainment in young adulthood. Astone and McLanahan (1991) found that father monitoring increased an adolescent's desire to go to college and complete their GED. These findings suggest that fathers play a more significant predictor of status attainment in young adulthood, when compared to mothers. Overall, 
the findings showed that an increase in status attainment in young adulthood decreases the likelihood of co-residency in young adult and adulthood, as shown in previous studies (Mitchell et al., 2006).

This study showed that the greater number of depressive symptoms in young adulthood increased the likelihood of co-residency in adulthood; however, this was only the case for males. The results showed a positive relationship between depressive symptoms in adolescence and in young adulthood, indicating that individuals who reported a greater number of depressive symptoms in adolescence are more likely to report depressive symptoms in young adulthood when compared to individuals who reported a lower number of depressive symptoms in adolescence. A greater number of depressive symptoms in young adulthood increased the likelihood of co-residency in adulthood, but only for males. Previous literature has found females to report higher levels of depressive symptoms than males (Merten \& Henry, 2011), however the findings from this current study indicate that depressive symptoms among females does not increase the likelihood of co-residency.

The study found a negative relationship between depressive symptoms and young adult status attainment in young adulthood. As predicted, young adult status attainment in young adulthood decreased the likelihood of co-residency in adulthood. Males who reported a higher young adult status attainment were less likely to co-reside with parents in young adulthood. In general, this study found that males are more likely to co-reside with parents in young adulthood and adulthood than females, other studies revealed similar findings (Fokkema \& Liefbroer, 2008; Smits et al., 2010). 
Race was found to be an important predictor of co-residency during adulthood, with racial/ethnic minority groups being more likely to co-reside than Whites, previous studies showed the same results (Choi, 2003). Asian males were more likely than White males to co-reside; where Hispanic females were more likely than White females to coreside. These results suggest that cultural norms may be a leading factor to adult children residing at home during adulthood. Collective cultures tend to have more of an expectation of co-residing at home for longer periods of time than Western cultures; they tend to remain at home until marriage (Aquilino, 1990; Mitchell et al., 2004). This study is one of the few that has examined co-residency with a U.S. population.

Asian, African American and Hispanics and males all showed to report having a greater relationship quality with their mother than Whites and females. This could be one the reasons to why these racial/ethnic groups are more likely to co-reside than Whites and females. This study speculates that certain minority groups may be more likely to coreside compared to Whites. Asian, African American and Hispanic cultures have more of an expectation to remain at home for longer periods of time; they do not enforce the autonomous lifestyles that White families tend to display. These groups may focus more on family and expect co-residency because of their close relationships, which shows to be a positive trait of co-residency, the opportunity to build and strengthen the parent-child relationship.

\section{Limitations}

While this study adds to the growing literature on adult children who co-reside with their parents, several limitations must be addressed. First, the co-residency measure lacks validity due to the time gap in data collection between Wave 3 and Wave 4 . If an 
individual reported living with a biological parent in Wave 3 and Wave 4, there may have been a period of time where the individual left the parental nest, which was not assessed during the data collection. Therefore, the co-residency measure in Wave 4 does not distinguish between boomerang adults and never leaving the nest adults, future research may want to investigate the different outcome variables for these individuals. Secondly, this study only included co-residing with biological parents in their co-residency measure. Doing so may have limited the amount of individuals who reported living at home during adulthood. Thirdly, this study did not take into account the economic difficulties that were going on in the United States during Wave 4. These economic hardships may have contributed to adult children co-residing with parents.

\section{Implications}

This study provides useful information about predictor variables that lead to coresidency in young adulthood, but with the help of the life course perspective, future research needs to examine co-residency as a predictor variable for transitions and outcomes later in life. Future research should use this research as a jumping off point for understanding the dynamics that occur with co-residency. This study provided some pattern about those who co-reside, but the research would be enriched if it could be studied further down the life course.

Gender has shown to be an important factor in predicting co-residency; however, little research has examined the dynamics to why males are more likely than females to co-reside. Future research should examine the individual characteristics between gender and co-residency. Furthermore, there has been an ambiguous perception regarding the phenomenon of adult children co-residing with parents during adulthood. This concept is 
neither a negative or positive transition but a trend in families, more specifically, a trend shaped by cultural norms and beliefs. Research has shown that Asian cultures are more acceptable of co-residency, where in the United States, this concept lacks clarity of the meaning behind this trend and where the trend is to head over time. The current study has begun to break apart the positive and negative implications of co-residing in adulthood. Some individuals may have chosen to co-reside because of the relationship quality with their parents, which has shown to be a positive aspect of co-residency, while others may have chosen to co-reside because of the lack status attainment in young adulthood and the inability to be self-sufficient, which, in some households, may be perceived as a negative implication of co-residency. Future research should investigate more conceptualized reasons to why individuals choose to co-reside.

\section{Conclusion}

Overall, the findings of this study add to the co-residency literature by examining co-residency through a longitudinal lens which gives this research the ability to examine the predicting variables that lead to co-residence in young adulthood and adulthood. The study also provided useful information about the unique long term influence of precocious life events. The study found that precocious life events did not directly predict co-residency, but did find the importance of parental relationship quality, gender and race in the likelihood of co-residing. The study also revealed the importance of status attainment in young adulthood in reducing the likelihood for co-residency.

Lastly, this study examined a sample that has yet to be used in the co-residency literature, it examined co-residency in late twenties and thirties whereas previous literature has only looked at early twenties. The study also examined the relationships 
between co-residency in young adulthood and adulthood and it found that those who reside in young adulthood are more likely to co-reside in adulthood when compared to those who never co-resided in young adulthood. As hypothesized in Figure 1, this study shows the beginning patterns of co-residency in adulthood. Future research needs to continue studying adult children who co-reside and develop a more in-depth pattern. 


\section{REFERENCES}

Alexander, K. (2001). The dropout process in life course perspective: Early risk facts at home and school. Teachers College Record, 103, 760-822.

Angrist, J. D., \& Krueger, A. (1991). Does compulsory school attendance affect schooling and earnings? Quarterly Journal of Economics, 106, 979-1014.

Aquilino, W. S. (1990). The likelihood of parent-adult child co-residence: Effects of family structure and parental characteristics. Journal of Marriage and the Family, $52,405-419$.

Arnett, J, J. (2000). Emerging adulthood: A theory of development from the late teens through the twenties. American Psychologist, 55, 469-480.

Arnett, J, J. (2001). Conceptions of the transition to adulthood among emerging adults in American ethnic groups. Journal of Adult Development, 8, 133-143.

Astone, N. M., \& McLanahan, S. S. (1991). Family structure, parental practices and high school completion. American Sociological Review, 56, 309-320.

Avery, R., Goldscheider, F., \& Speare, A., JR. (1992). Feathered nest/gilded cage: The effects of parental resources on young adults' leaving home. Demography, 29, $375-388$

Baron, R. M., \& Kenny, D. A. (1986). The moderator-mediator variable distinction in social psychological research: conceptual, strategic and statistical considerations. Journal of Personality and Social Psychology, 51, 1173-1182.

Beaupre, P., Turcotte, P., \& Milan, A. (2006). Junior comes back home: Trends and predictors of returning to the parental home. Canadian Social Trends, 82, 28-34. 
Boss, P. E. (1992). Primacy of perception in family stress theory and measurement. Journal of Family Psychology, 6, 113-119.

Boyd, M., \& Norris, D. (1999). The crowded nest: Young adults at home. Canadian Social Trends, Statistics Canada, Catalogue No. 11-008.

Bradley, T., Cupples, M. E., \& Irvine, H. (2002). A case control study of deprivation triangle: Teenage motherhood, poor educational achievement and unemployment. International Journal of Adolescent Medicine and Health, 14, 117-123.

Bynner, J. (2000). Social change and the sequencing of developmental transitions. In L. Crockett \& R. Silbereisen (Eds.), Negotiating adolescence in times of social change (pp. 89-103). Cambridge: Cambridge University Press.

Campbell, T., \& Duffy, M. (1998). Dropping out of secondary school: A descriptive discriminant analysis of early dropouts, late dropouts, alternative completers, and stayins. Research in the Schools, 5, 1-10.

Census Bureau (1999). Statistical abstract of the United States. Washington DC: US Department of Commerce.

Chen, Z. Y., \& Kaplan, H. B. (1999). Explaining the impact of family structure during adolescence on adult educational attainment: A longitudinal study. Applied Behavioral Science Review, 7, 23-40.

Cherlin, A. J. (2010). Demographic trends in the United States: A review of research in the 2000's. Journal of Marriage and Family, 72, 403-419. doi: 10. 111/j.741-3737.2010.00710.x 
Cherry, A. L., Dillon, M. E., \& Rug, D. (2001). Teenage pregnancy: A global view. Westport, CT: Greenwood Press.

Choi, N. G. (2003). Coresidence between unmarried aging parents and their adult children: Who moved in with whom and why? Research on Aging, 25, 384-404. doi:10.1177/0164027503025004003

Cobb, N. J. (2007). Adolescence: Continuity, change, and diversity. New York: McGraw-Hill.

Cooney, T. M., \& Mortimer, J. T. (1999). Family structure differences in the timing of leaving home: Exploring mediating factors. Journal of Research on Adolescence, 9, 367-393.

Cote, J. E., \& Allahar, A. L. (1994). Generation on hold: Coming of age in the twentieth century. Toronto: Stoddart Publishing.

Da Vanzo, J., \& Goldscheider, F. (1990). Coming home again: Returns to the parental home of young adults. Population Studies, 44, 241-255.

doi. $10.1080 / 0032472031000144576$

Danziger, S.K., Corcoran, M., Danziger, S. H., Heflin, C., Kalil, A., Levine., J., Rosen D., Seefeldt, K., Siefert, K., \& Tolman, R. (2000). Barriers to the employment of welfare recipients, In R.Cherry \& W. Rodgers (Eds.), Prosperity for all? The economic boom and African Americans. New York: Russell Sage Foundations.

Elder, G. H. (1985). Perspectives on the life course. In G. Elder (Eds.), Life course perspective dynamics (23-49). Ithaca: Cornell University Press

Elder, G. H. (1992). Models of the life course. Contemporary Sociology, 21, 632-635. 
Elder, G. (1994). Time, human agency, and social change: Perspective on the life course. Social Psychology Quarterly, 57, 4-14.

Elder, G. H. (1998). The Life course perspective as developmental theory. Child Development, 69, 1-13.

Entwisle, D. R., \& Alexander, K. L., \& Olson, L. S. (2005). Urban teenagers: Work and dropout. Youth and Society, 37, 3-32. doi:10.177/0044118X04268313

Figueiredo, B., Bifulco, A., Pacheco, A., Costa, R., \& Magarinho, R. (2006). Teenage pregnancy, attachment style, and depression: A comparison of teenage and adult pregnant women in a portugese series. Attachment \& Human Development, 8, 123-138.

Fletcher, J. M. (2008). Adolescent depression: Diagnosis, treatment, and educational attainment. Health Economics, 17, 1215-1235. doi:10.002/hec.319.

Fokkema, T., \& Liefbroer, A. C. (2008). Trends in living arrangements in Europe: Convergence of divergence? Demographic Research, 19, 1351-1418.

Furman, E. (2005). Boomerang nation: How to survive living with your parents...The second time around. New York: Fireside.

Garasky, S. (2002). Where are they going? A comparison of urban and rural youths' locational choices after leaving the parental home. Social Science Research, 31, 409-431.

Ge, X., Conger, R.D., \& Elder, G. H. (2001). The relation between puberty and psychological distress in adolescent boys. Journal of Research on Adolescence, $11(1), 142-151$. 
Gillmore, M., R., Lewis, S., Lohr, M. J., Spencer, M. S., \& White, R. (1997). Rapid repeat pregnancies among adolescent mothers. Journal of Marriage and the Family, 57, 536-550.

Goldscheider, F. K., \& Goldscheider, C. (1998). The effects of childhood family structure on leaving and returning home. Journal of Marriage and the Family, $60,745-756$.

Hammond, C. (2002). What is it about education that makes us health? Exploring the education-health connection. International Journal of Lifelong Education, 21, 551-571. doi:10.080/0260137022000016767

Hardy, J. B., Astone, N.M., Brookes-Gunn, J., Shaoro, S., \& Miller, T. L. (1998). Like mother, like child: Intergenerational patterns of age at first birth and associations with childhood and adolescent characteristics and adult outcomes in the second generation. Developmental Psychology, 34, 1220-1232.

Havighurst, R. (1948). Developmental tasks and education. Chicago: University of Chicago Press.

Heinicke, C. M. (2002). The transition to parenting. In M. H. Bornstein (Eds.), Handbook of parenting: Vol 3. Being and becoming a parent (2 ${ }^{\text {nd }}$ ed., pp. 363-388). Mahwah, NY: Lawrence Erlbaum.

Hobcraft, J., \& Kiernan, K. (2001). Childhood poverty, early motherhood and adult social exclusion. British Journal of Sociology, 52, 495-517.

Irvine, H., Bradley, T., Cupples, M., \& Boohan, M. (1997). The implications of teenage pregnancy and motherhood for primary health: Unresolved issues. British Journal of General Practice, 47, 323-326. 
Kalil, A., \& Kunz, J. (2002). Teenage childbearing, marital status and depressive symptoms in later life. Child Development, 73, 1748-1760.

Kalil, A., \& Ziol-Guest, K. M. (2008). Teacher support, school goal structures, and teenage mothers' school engagement. Youth Society, 39, 524-548. doi: 10.177/0044118X07301001

Kaplan, E. (1996). Black teenage mothers and their mothers: The impact of adolescents childbearing on daughters' relations with mothers. Social Problems, 43, 427-443.

Karmakar, S. D., \& Breslin, F. C. (2008). The role of educational level and job characteristics on the health of young adults. Social Science \& Medicine, 66, 2011-2022. doi: 10. 016/j.socscimed.2008.01.017.

Kiernan, K. E. (1997). Becoming a young parent: A longitudinal study of associated factors. British Journal of Sociology, 48, 406-428.

Kin, E., \& Beyers, W. (2010). Failure to launch, failure to achieve criteria for adulthood? Journal of Adolescent Research, 20, 1-35 doi: 10.77/0743558410371126

Kreiter, M.S. (2003). Grown up at 21? No way. Washington, DC: United Press International.

Koster, A., Bosma, H., Kempen, G. I., Penninx, B. W., Beekman, A.T., Deeg, D.J., van Eijk, J. (2006). Socioeconomic differences in incident depression in older adults: The role of psychosocial factors, physical health status, and behavioral factors. Journal of Psychosomatic Research, 61, 619-627. dio:10.016/j.jpsy-chores.2006.05.009

Leadbeater, B. J., \& Way, N. (2001). Growing up fast: Transitions to adulthood of innercity adolescent mothers. Mahwah, NJ: Lawrence Erlbaum. 
Lee, H., Harris, K. M., \& Gordon-Larsen, P. (2009). Life course perspective on the links between poverty and obesity during the transition to young adulthood. Population Research and Policy Review, 28, 505-532. doi: 10.007/s11113-008-9115-4

Lichter, D., \& Qian, Z. (2004). Marriage and family in a multiracial society. In R. Farley \& J. Haaga (Eds.), The American People: Census 2000 (pp. 169-200). New York: Russell Sage.

Mallett, S., \& Rosenthal, D. (2009). Physically violent mothers are a reason for young people's leaving home. Journal of Interpersonal Violence, 24, 1165-1174. doi: $10.177 / 0886260508322188$

Masten, A. S., Rosiman, G. I., Long, J. D., Burt, K. B., Obradovic, J., Riley, J. M., Boelcke-Stennes, K., \& Tellegen, A. (2005). Developmental cascades: Linking academic achievement, externalizing and internalizing symptoms over 20 years. Developmental Psychology, 41, 733-746. doi: 10. 037/0012-1649.41.5.733

Mathews, T.J., \& Hamilton, B.E. (2002). Mean age of mother, 1970-2000. National Vital Statistics Reports, 51. Hyattsville, MD: National Center for Health Statistics.

Merten, M. J., \& Henry, C. S. (2011). Family structure, mother-daughter relationship quality, race and ethnicity and adolescent girls' health risks. Journal of Divorce \& Remarriage, 52, 164-186. doi: 10.080/10502556.2011.556966

Merten, M. J., Wickrama, K. A., \& Williams, A. L. (2008). Adolescent obesity and young adult psychosocial outcomes: Gender and racial differences. Journal of Youth and Adolescence, 37, 1111-1122. doi: 10. 007/s10964-008-9281-z 
Mitchell, B. A. (1998). Too close for comfort? Parental assessments of "boomerang kid" living arrangements. Canadian Journal of Sociology, 23, 21-46.

Mitchell, B. A. (2006). The boomerang age from childhood to adulthood: Emergent trends and issues for aging families. Canadian Studies in Population, 33, 155178.

Mitchell, B., Wister, A., \& Burch, T. (1989). The family environment and leaving the parental home. Journal of Marriage and the Family, 51, 605-613.

Mitchell, B. A., Wister, A. V., \& Burch, T. K (2002). “There's no place like home”: An analysis of young adults' mature coresidency in Canada. International Journal of Aging and Human Development, 54(1), 57-84.

doi: 10.2190/DN8G-36ER-NHYK-64EN

Mitchell, B. A., Wister, A. V., \& Gee, E. M. (2004). The ethnic and family nexus of homeleaving and returning among Canadian young adults. Canadian Journal of Sociology, 29, 543-575.

Mollborn, S. (2007). Making the best of a bad situation: Material resources and teenage parenthood. Journal of Marriage and Family, 69, 92-104.

Mollborn, S., \& Moringstar, E. (2007). Investigating the relationship between teenage childbearing and psychological distress using longitudinal evidence. Journal of Health and Social Behavior, 50, 310-326.

Nelson, L, J., \& Barry, C. M. (2005). Distinguishing features of emerging adulthood: The role of self-classification as an adult. Journal of Adolescent Research, 20, 242-262. doi: $10.77 / 0743558404273074$ 
Nesman, T. M. (2007). A participatory study of school dropout and behavioral health of Latino adolescents. The Journal of Behavioral Health Services \& Research, 34, 414-430.

Oreopoulos, P. (2007). Do dropouts drop out too soon? Wealth, health and happiness from compulsory school. Journal of Public Economics, 91, 2213-2229.

Prater, L. P. (1995). Never married/biological teen mother headed household. Marriage \& Family Review, 20, 305-323.

Radloff, L. S. (1977). The CES-D scale: A self-report depressive symptoms scale for research in the general population. Applied Psychological Measurement, 1, 385401.

Sassler, S., Ciambrone, D., \& Benway, G. (2008). Are they really mama's boys/daddy's girls? The negotiation of adulthood upon returning to the parental home. Sociological Forum, 23, 670-698. doi: 10.111/j.573-7861.2008.00090.x.

Schnaiberg, A., \& Goldenberg, S. (1989). From empty nest to crowded nest: The dynamics of incompletely-launched young adults. Social Problems, 36(3), 251269. Retrieved from http://www.jstor.org/stable/800694

Schulz, A. J., Isreal, B. A., Zenk, S. N., Parker, E. A., Lichtenstein, R., Shellman-Weir, S., \& Klem, L. (2006). Psychosocial stress and social support as mediators of relationships between income, length of residence and depressive symptoms among African American women on Detroit's eastside. Social Science \& Medicine, 62, 510-522. 
Seiffge-Krenke, I. (2006). Leaving home or still in the nest? Parent-child relationships and psychological health as predictors of different leaving home patterns. Developmental Psychology, 42, 864-876.

Settersten, R. A. (2004). Age structuring and the rhythm of the life course. In J. Mortimer, \& M. Shanahan (Eds.) Handbook of the Life course perspective (pp. 81-98). New York: Springer.

Settersten, R.A., Jr., Furstenberg, F.K. Jr. \& Rumbaut, R.G. (2005). On the Frontier of Adulthood: Theory, Research, and Public Policy. Chicago, IL: The University of Chicago Press.

Shaw, M., Lawlor, D. A., \& Najman, J. M. (2006). Teenage children of teenage mothers: Psychological, behavioral, and health outcomes from an Australian prospective longitudinal study. Social Science \& Medicine, 62, 2526-2539.

Smits, A., Van Gaalen, R. I., \& Mulder, C. H. (2010). Parent-child coresidence: Who moves in with whom and for whose needs? Journal of Marriage and Family, 72, 1022-1033. doi:10.1111/j.1741-3737.2010.00746.x

Storm, R., \& Boster, F. J. (2007). Dropping out of high school: A meta-analysis assessing the effects of messages in the home and in school. Communication Education, $56,433-452$.

Stryker, S., \& Burke, P. J. (2000). The past, present, and future of an identity theory. Social Psychology Quarterly, 63, 284-297.

Topitzes, J., Godes, O., Mersky, J. P., Ceglarek, S., \& Reynolds, A. J. (2009). Educational success and adult health: Findings from the Chicago longitudinal study. Society for Prevention Research, 10, 175-195. 
Uhlenberg, P., \& Mueller, M. (2003). Family context and individual well-being: Patterns and mechanisms in Life course perspective perspective. In J. Mortimer, \& M.

Shanahan (Eds.) Handbook of the Life course perspective (pp. 81-98). New York: Springer.

US Department of Education. (2009). High school dropout and completion rates in the united states: 2007.

Retrieved August 23, 2010, http://nces.ed.gov/pubs2009/2009064.pdf

U. S. Census. (2004). "Young adults living at home: 1960-present.

Retrieved from http://www.census.gov/population/socdemo/hh-fam/tabAD-1.pdf

Ward, R.A., \& Spitze, G. D. (2007). Nestleaving and coresidence by young adult children: The role of family relations. Research on Aging, 29, 257-277. doi: $10.177 / 0164027506298225$

Webbink, D., Martin, N. G., \& Visscher, P. M. (2008). Does teenage childbearing increase smoking, drinking and body size? Journal of Health Economics, 27, 888903. doi:10.016/j.jhealeco.2008.02.005

White, L. K., \& Rogers, S. J. (1997). Strong support but uneasy relationships: Coresidence and adult children's relationships with their parents. Journal of Marriage and Family, 59, 62-76

Wickrama, K. A.S., Bryant, C. (2003). Community context of social resources and adolescent mental health. Journal of Marriage and Family, 65, 850-866. doi. 10.1111/j.1741-3737.2003.00850.x 
Wickrama, K. A.S., Conger, R. D., Wallace, L. E., \& Elder, G. H. (2003). Linking early social risks to impaired physical health during the transition to adulthood. Journal of Health and Social Behavior, 44, 61-74.

Wickrama, K. A., \& Merten, M. J. \& Elder, G. H. (2005). Community influence on precocious transitions to adulthood: Racial differences and mental health consequences. Journal of Community Psychology, 33, 639-653. doi: 10.002/jcop.20076

Woodward, L., Fergusson, D. M., \& Horwood, J. L. (2001). Risk factors and life processes associated with teenage pregnancy: Results of a prospective study from birth to 20 years. Journal of Marriage and Family, 63, 1170-1184. 
Table 1. Zero order correlations among study variables $(N=10,061)$

\begin{tabular}{|c|c|c|c|c|c|c|c|c|c|c|c|c|c|c|c|c|}
\hline Variables & 1 & 2 & 3 & 4 & 5 & 6 & 7 & 8 & 9 & 10 & 11 & 12 & 13 & 14 & & 15 \\
\hline 1. Co-residency-adulthood & --- & & & & & & & & & & & & & & & \\
\hline 2. Co-residency-young adulthood & $.25^{* *}$ & --- & & & & & & & & & & & & & & \\
\hline 3. Co-residency - both & $.80 * *$ & $.43 * *$ & --- & & & & & & & & & & & & & \\
\hline 4. Precocious life events & $.01-$ & $-.09 * *$ & -.02 & --- & & & & & & & & & & & & \\
\hline 5. Depressive symptoms (W3) & $.07 * *$ & .01 & $.05^{* *}$ & $.07 * *$ & --- & & & & & & & & & & & \\
\hline 6. Depressive symptoms (W2) & $.05^{* *}$ & -.01 & $.04 * *$ & $.15^{* *}$ & $.37 * *$ & --- & & & & & & & & & & \\
\hline 7. Young adult status attainment & $-.14 * *$ & $-.15^{* *}$ & $-.14 * *$ & $-.18 * *$ & $-.18 * *$ & $-.16^{* *}$ & --- & & & & & & & & & \\
\hline 8. Relationship quality-father & $-.03 * *$ & $-.04 * *$ & $-.05 * *$ & $-.03 * *$ & $-.18 * *$ & $-.13 * *$ & $.12 * *$ & --- & & & & & & & & \\
\hline 9. Relationship quality-mother & $.21 * *$ & $.82 * *$ & $.36^{* *}$ & $-.03 * *$ & .03 & .02 & $-.17 * *$ & $-.05 * *$ & --- & & & & & & & \\
\hline 10. Family economic hardship (W1) & .01 & $-.04 * *$ & .01 & $.14 * *$ & $.07 * *$ & $.10 * *$ & $-.18 * *$ & $-.04 * *$ & .02 & --- & & & & & & \\
\hline 11. Biological parents-married (W2) & $.04 * *$ & $.11 * *$ & $.05 * *$ & $-.18 * *$ & $-.08 * *$ & $-.11 * *$ & $.14 * *$ & $.14 * *$ & $.03 * *$ & $-.23 * *$ & --- & & & & & \\
\hline 12. African American & $.06^{* *}$ & $.04 * *$ & $.06 * *$ & $.05 * *$ & $.06^{* *}$ & $.04 * *$ & $-.11 * *$ & -.02 & $.04 * *$ & .185 & $-.21 * *$ & --- & & & & \\
\hline 13. Hispanic & $.09 * *$ & $.09 * *$ & $.10 * *$ & $.04 * *$ & $.04 * *$ & $.08 * *$ & $-.07 * *$ & $-.04 * *$ & $.10 * *$ & $.04 * *$ & $.03 * *$ & $-.22 * *$ & --- & & & \\
\hline 14. Asian & $.08 * *$ & $.08 * *$ & $.07 * *$ & $-.05^{* *}$ & $.04 * *$ & $.05 * *$ & $.02 *$ & $-.06 * *$ & $.06 * *$ & $.05 * *$ & $.08 * *$ & $-.13 * *_{-}$. & $11 * *$ & --- & & \\
\hline 15. Native American & -.01 & -.01 & .01 & .01 & .01 & .01 & -.01 & .01 & -.01 & $.02 *$ & -.02 & $-.05 * *_{-}$. & $.04 * *_{-}$ & $-.02 *$ & --- & \\
\hline 16. Female & $-.06 * *$ & $-.09 * *$ & $-.06 * *$ & $-.04 * *$ & $.11^{* *}$ & $.16 * *$ & $.03 *$ & $-.03 *$ & $-.07 * *$ & $.04 * *$ & $-.03 * *$ & $.04 * *$ & .02 & $-.03 * *$ & .01 & \\
\hline
\end{tabular}

$* \mathrm{p}<.05 . \quad * * \mathrm{p}<.01$


Table 2. Descriptive statistics for study variables $(N=10.061)$

\begin{tabular}{|c|c|c|c|c|}
\hline Variable & $M$ & $\%$ & $S D$ & Range \\
\hline Co-residence with parents (W3) & ---- & $42 \%$ & 0.49 & $0.00-1.00$ \\
\hline Co-residence with parents (W4) & ----- & $17 \%$ & 0.38 & $0.00-1.00$ \\
\hline Co-residence with parents (W3 \& 4) & ----- & $11 \%$ & 0.32 & $0.00-1.00$ \\
\hline Precocious life events & 0.36 & ----- & 0.62 & $0.00-5.00$ \\
\hline Depressive symptoms (W3) & 4.68 & ----- & 4.09 & $0.00-27.00$ \\
\hline Depressive symptoms (W4) & 5.29 & ----- & 4.11 & $0.00-27.00$ \\
\hline Young adult status attainment & 2.75 & ----- & 0.80 & $1.00-5.00$ \\
\hline Relationship quality-father & 12.94 & ----- & 3.00 & $3.00-15.00$ \\
\hline Relationship quality-mother & 8.48 & ----- & 4.83 & $1.00-15.00$ \\
\hline Family Economic Hardship & 0.28 & ----- & 0.28 & $0.00-3.00$ \\
\hline Biological parents-married (W2) & ----- & $53 \%$ & 0.50 & $0.00-1.00$ \\
\hline White & ----- & $56 \%$ & 0.50 & $0.00-1.00$ \\
\hline African American & ----- & $21 \%$ & 0.41 & $0.00-1.00$ \\
\hline Hispanic & ----- & $15 \%$ & 0.36 & $0.00-1.00$ \\
\hline Asian & ----- & $6 \%$ & 0.24 & $0.00-1.00$ \\
\hline Native American & ----- & $1 \%$ & 0.08 & $0.00-1.00$ \\
\hline Female & ----- & $55 \%$ & 0.50 & $0.00-1.00$ \\
\hline Age (W2) & 16.16 & ----- & 1.64 & $11.00-20.00$ \\
\hline Age (W3) & 21.60 & ---- & 1.64 & $18.00-26.00$ \\
\hline Age (W4) & 28.14 & ----- & 1.65 & $24.00-33.00$ \\
\hline
\end{tabular}


Table 3. Co-residency in young adulthood and adulthood, by gender $(N=10,061)$

\begin{tabular}{lcc}
\hline Variable & Male & Female \\
\hline Never co-reside & $48 \%(2,189)$ & $58 \%(3,148)$ \\
Co-reside in Wave 3 only & $32 \%(1,485)$ & $28 \%(1,516)$ \\
Co-reside in Wave 4 only & $5 \%(258)$ & $5 \%(288)$ \\
Co-reside in Wave $3 \& 4$ & $14 \%(630)$ & $10 \%(547)$ \\
\hline
\end{tabular}


Table 4. Co-residency in young adulthood and adulthood, by race $(N=10,061)$

\begin{tabular}{lclll}
\hline Variable & $\begin{array}{c}\text { Never } \\
\text { Co-reside }\end{array}$ & $\begin{array}{c}\text { Co-reside } \\
\text { W3 Only }\end{array}$ & $\begin{array}{c}\text { Co-reside } \\
\text { W4 Only }\end{array}$ & $\begin{array}{r}\text { Co-reside } \\
\text { W3\&W4 }\end{array}$ \\
\hline White (5,667) & $59 \%(3,361)$ & $29 \%(1,623)$ & $5 \%(267)$ & $7 \%(416)$ \\
African American $(2,145)$ & $48 \%(1,041)$ & $30 \%(638)$ & $7 \%(139)$ & $15 \%(327)$ \\
Hispanic (1,550) & $42 \%(655)$ & $33 \%(509)$ & $6 \%(87)$ & $19 \%(299)$ \\
Asian (621) & $38 \%(235)$ & $34 \%(211)$ & $8 \%(50)$ & $20 \%(125)$ \\
Native American (78) & $58 \%(45)$ & $26 \%(20)$ & $3 \%(3)$ & $13 \%(10)$ \\
\hline
\end{tabular}


Table 5. Co-residency in young adulthood and adulthood, by age $(N=10,061)$

\begin{tabular}{|c|c|c|}
\hline Variable & Young Adulthood & Adulthood \\
\hline \multicolumn{3}{|l|}{ Age } \\
\hline 18 & $68 \%(86)$ & ------ \\
\hline 19 & $56 \%(625)$ & ------ \\
\hline 20 & $48 \%$ (754) & ------ \\
\hline 21 & $42 \%(778)$ & ------ \\
\hline 22 & $40 \%$ (859) & ------ \\
\hline 23 & $35 \%(704)$ & ------ \\
\hline 24 & $30 \%(294)$ & $21 \%(5)$ \\
\hline 25 & $29 \%(71)$ & $24 \%$ (119) \\
\hline 26 & $30 \%(7)$ & $18 \%(252)$ \\
\hline 27 & ------ & $19 \%$ \\
\hline 28 & ------ & $16 \%$ \\
\hline 29 & ------ & $17 \%(362)$ \\
\hline 30 & ------ & $14 \%(228)$ \\
\hline 31 & ------ & $16 \%(91)$ \\
\hline 32 & ------ & $21 \%(22)$ \\
\hline 33 & ------ & $0 \%(8)$ \\
\hline
\end{tabular}


Table 6. Co-residency in young adulthood and adulthood, by race and gender

\begin{tabular}{llll}
\hline Variable & Co-reside W3 & Co-reside W4 & Co-reside W3\& W4 \\
\hline White Males (2,592) & $41 \%(1,054)$ & $14 \%(352)$ & $9 \%(231)$ \\
White Females (3,075) & $32 \%(985)$ & $11 \%(331)$ & $6 \%(185)$ \\
African American Males (884) & $51 \%(447)$ & $26 \%(232)$ & $19 \%(170)$ \\
African American Females (1,261) & $41 \%(518)$ & $19 \%(234)$ & $12 \%(157)$ \\
Hispanic Males (731) & $56 \%(413)$ & $27 \%(194)$ & $21 \%(152)$ \\
Hispanic Females (819) & $48 \%(395)$ & $23 \%(192)$ & $18 \%(147)$ \\
Asian Males (320) & $58 \%(186)$ & $32 \%(102)$ & $22 \%(71)$ \\
Asian Females (301) & $50 \%(150)$ & $24 \%(73)$ & $18 \%(54)$ \\
Native American Males (35) & $43 \%(15)$ & $23 \%(8)$ & $17 \%(6)$ \\
Native American Females (43) & $35 \%(15)$ & $14 \%(5)$ & $9 \%(4)$ \\
\hline
\end{tabular}


Table 7. Unstandardized regression coefficients (t-values) for independent variables on Young Adult Outcomes for Males

\begin{tabular}{|c|c|c|c|c|}
\hline & \multicolumn{4}{|c|}{ Dependent Variables } \\
\hline & $\begin{array}{c}\text { Depressive } \\
\text { Symptoms (W3) }\end{array}$ & $\begin{array}{c}\text { Young adult } \\
\text { status attainment (W3) }\end{array}$ & $\begin{array}{l}\text { Relationship } \\
\text { quality with father (W3) }\end{array}$ & $\begin{array}{l}\text { Relationship } \\
\text { quality with mother (W3) }\end{array}$ \\
\hline Precocious events (W2) & $\begin{array}{l}-0.09 \\
(-0.82)\end{array}$ & $\begin{array}{l}-0.16^{* * * *} \\
(6.34)\end{array}$ & $\begin{array}{c}0.08 \\
(1.16)\end{array}$ & $\begin{array}{l}-0.26 \\
(-1.60)\end{array}$ \\
\hline Depressive symptoms (W3) & $\begin{array}{l}--- \\
---\end{array}$ & $\begin{array}{l}-0.03 * * * \\
(5.94)\end{array}$ & $\begin{array}{l}-0.09 * * * \\
(-7.29)\end{array}$ & $\begin{array}{l}-0.03 \\
(-1.14)\end{array}$ \\
\hline Young adult status attainment (W3) & $\begin{array}{l}-0.51 * * * \\
(5.94)\end{array}$ & -- & $\begin{array}{l}0.11^{*} \\
(2.08)\end{array}$ & $\begin{array}{l}-1.29 * * * \\
(-10.87)\end{array}$ \\
\hline Relationship quality with father (W3) & $\begin{array}{l}-0.22 * * * \\
(-7.29)\end{array}$ & $\begin{array}{c}0.01 * \\
(2.08)\end{array}$ & --- & $\begin{array}{l}-0.06 \\
(-1.35)\end{array}$ \\
\hline Relationship quality with mother (W3) & $\begin{array}{l}-0.02 \\
(-1.14)\end{array}$ & $\begin{array}{l}-0.03 * * * \\
(10.87)\end{array}$ & $\begin{array}{l}-0.01 \\
(-1.35)\end{array}$ & --- \\
\hline African American & $\begin{array}{l}0.41^{*} \\
(2.17)\end{array}$ & $\begin{array}{l}-0.13^{* *} \\
(-3.18)\end{array}$ & $\begin{array}{c}0.15 \\
(1.28)\end{array}$ & $\begin{array}{l}1.04 * * * \\
(3.87)\end{array}$ \\
\hline Hispanic & $\begin{array}{c}0.15 \\
(0.86)\end{array}$ & $\begin{array}{l}-0.17 * * \\
(-4.37)\end{array}$ & $\begin{array}{l}-0.13 \\
(-1.18)\end{array}$ & $\begin{array}{l}1.73 * * * \\
(6.92)\end{array}$ \\
\hline Asian & $\begin{array}{c}0.36 \\
(1.33)\end{array}$ & $\begin{array}{l}-0.05 \\
(0.88)\end{array}$ & $\begin{array}{l}-0.54 * * \\
(-3.23)\end{array}$ & $\begin{array}{l}1.26^{* *} \\
(3.36)\end{array}$ \\
\hline Depressive symptoms (W2) & $\begin{array}{l}0.32 * * * \\
(18.35)\end{array}$ & $\begin{array}{l}-0.01 \\
(-1.27)\end{array}$ & $\begin{array}{l}-0.02 \\
(-1.96)\end{array}$ & $\begin{array}{c}0.02 \\
(0.57)\end{array}$ \\
\hline Family economic hardship (W1) & $\begin{array}{l}0.23^{*} \\
(2.07)\end{array}$ & $\begin{array}{l}-0.12 * * * \\
(-4.81)\end{array}$ & $\begin{array}{l}-0.01 \\
(-0.12)\end{array}$ & $\begin{array}{c}0.25 \\
(1.54)\end{array}$ \\
\hline Biological parents married (W2) & $\begin{array}{c}0.26 \\
(1.75)\end{array}$ & $\begin{array}{l}0.13^{* * *} \\
(3.95)\end{array}$ & $\begin{array}{l}0.70 * * * \\
(7.60)\end{array}$ & $\begin{array}{c}0.47^{*} \\
(2.28)\end{array}$ \\
\hline R-square & 0.16 & 0.12 & 0.06 & 0.08 \\
\hline
\end{tabular}

$* \mathrm{p}<.05 . \quad * * \mathrm{p}<.01 . \quad * * * \mathrm{p}<.001$. 
Table 8. Unstandardized regression coefficients (t-values) for independent variables on Young Adult Outcomes for Females

\begin{tabular}{|c|c|c|c|c|}
\hline & \multicolumn{4}{|c|}{ Dependent Variables } \\
\hline & $\begin{array}{c}\text { Depressive } \\
\text { Symptoms (W3) }\end{array}$ & $\begin{array}{c}\text { Young adult } \\
\text { status attainment (W3) }\end{array}$ & $\begin{array}{l}\text { Relationship } \\
\text { quality with father (W3) }\end{array}$ & $\begin{array}{l}\text { Relationship } \\
\text { quality with mother (W3) }\end{array}$ \\
\hline Precocious Events (W2) & $\begin{array}{l}-0.02 \\
(-0.12)\end{array}$ & $\begin{array}{l}-0.20 * * * \\
(-7.34)\end{array}$ & $\begin{array}{l}-0.06 \\
(-0.67)\end{array}$ & $\begin{array}{l}-0.68 * * * \\
(3.94)\end{array}$ \\
\hline Depressive symptoms (W3) & --- & $\begin{array}{l}-0.03 * * * \\
(-7.59)\end{array}$ & $\begin{array}{l}-0.09 * * * \\
(-8.22)\end{array}$ & $\begin{array}{l}-0.02 \\
(-0.97)\end{array}$ \\
\hline Young adult status attainment (W3) & $\begin{array}{l}-0.69 * * * \\
(-7.59)\end{array}$ & --- & $\begin{array}{l}0.17 * * \\
(3.16)\end{array}$ & $\begin{array}{l}-1.13^{* * *} \\
(10.12)\end{array}$ \\
\hline Relationship quality with Father (W3) & $\begin{array}{l}-0.24 * * * \\
(-8.22)\end{array}$ & $\begin{array}{l}0.02 * * \\
(3.16)\end{array}$ & --- & $\begin{array}{l}-0.09^{*} \\
(-2.36)\end{array}$ \\
\hline Relationship quality with Mother (W3) & $\begin{array}{l}-0.01 \\
(-0.97)\end{array}$ & $\begin{array}{l}-0.03 * * * \\
(-10.12)\end{array}$ & $\begin{array}{l}-0.02 * \\
(-2.36)\end{array}$ & --- \\
\hline African American & $\begin{array}{c}0.26 \\
(1.34)\end{array}$ & $\begin{array}{l}-0.08 * \\
(-2.02)\end{array}$ & $\begin{array}{l}-0.29^{*} \\
(-2.45)\end{array}$ & $\begin{array}{l}1.16^{* * * *} \\
(4.79)\end{array}$ \\
\hline Hispanic & $\begin{array}{c}0.24 \\
(1.22)\end{array}$ & $\begin{array}{l}-0.08^{*} \\
(-2.08)\end{array}$ & $\begin{array}{l}-0.25^{*} \\
(-2.13)\end{array}$ & $\begin{array}{l}1.73 * * * \\
(7.22)\end{array}$ \\
\hline Asian & $\begin{array}{c}0.38 \\
(1.23)\end{array}$ & $\begin{array}{c}0.06 \\
(0.96)\end{array}$ & $\begin{array}{l}-0.62 * * \\
(-3.32)\end{array}$ & $\begin{array}{l}1.53 * * * \\
(3.96)\end{array}$ \\
\hline Depressive symptoms (W2) & $\begin{array}{l}0.31^{* * * *} \\
(19.48)\end{array}$ & $\begin{array}{l}-0.02 * * \\
(-3.19)\end{array}$ & $\begin{array}{l}-0.03 * * \\
(-3.03)\end{array}$ & $\begin{array}{l}-0.01 \\
(-0.45)\end{array}$ \\
\hline Family economic hardship (W1) & $\begin{array}{c}-0.03 \\
(-0.24)\end{array}$ & $\begin{array}{l}-0.13 * * * \\
(-5.66)\end{array}$ & $\begin{array}{l}-0.04 \\
(-0.62)\end{array}$ & $\begin{array}{l}-0.01 \\
(-0.23)\end{array}$ \\
\hline Biological parents married (W2) & $\begin{array}{l}-0.02 \\
(-0.12)\end{array}$ & $\begin{array}{l}0.15^{* * *} \\
(4.92)\end{array}$ & $\begin{array}{l}0.66^{* * *} \\
(6.90)\end{array}$ & $\begin{array}{c}0.16 \\
(0.79)\end{array}$ \\
\hline R-square & 0.17 & 0.13 & 0.08 & 0.06 \\
\hline
\end{tabular}

$* \mathrm{p}<.05 . \quad * * \mathrm{p}<.01 . \quad * * * \mathrm{p}<.001$. 
Table 9. Logistic regression coefficients (odds ratios) for the Effects of Adolescent and Young Adulthood Factors and Race/Ethnicity on Male Co-Residence in Both Young Adulthood and Adulthood.

Independent Variables

Adolescence (W2)

Precocious events

Depressive symptoms

Biological parents married

Family economic hardship

\section{Young adulthood (W3)}

Depressive symptoms

Young adult status attainment

Relationship quality with father

Relationship quality with mother

Biological parents married

\section{Race/Ethnicity}

African American

$\begin{array}{ccc}-0.02 & 0.01 & 0.01 \\ (0.99) & (1.01) & (1.00) \\ 0.06 * * * & 0.04^{*} & 0.02 \\ (1.06) & (1.04) & (1.02) \\ 0.16 & -0.30 & -0.26 \\ (1.17) & (0.74) & (0.77) \\ 0.07 & 0.02 & 0.01 \\ (1.07) & (1.02) & (1.01)\end{array}$

\section{Model $1 \quad$ Model $2 \quad$ Model 3}

$\begin{array}{ll}0.05 * * & 0.04 * * \\ (1.05) & (1.05) \\ -0.55 * * * & -0.54 * * * \\ (0.58) & (0.58) \\ -0.08 * * & -0.07 * * \\ (0.93) & (0.93) \\ 0.23 * * * & 0.23 * * * \\ (1.26) & (1.25) \\ 0.75 * * * & 0.69 * * * \\ (2.12) & (2.00)\end{array}$

$0.72 * * *$

Hispanic

(2.06)

$0.55^{* * *} *$

(1.74)

Asian

$1.01 * * *$

(2.75)

$* \mathrm{p}<.05 . \quad * * \mathrm{p}<.01 . \quad * * * \mathrm{p}<.001$. 
Table 10. Logistic regression coefficients (odds ratios) for the Effects of Adolescent and Young Adulthood Factors and Race/Ethnicity on Female Co-Residence in Both Young Adulthood and Adulthood.

Independent Variables

Adolescence (W2)

Precocious events

Depressive symptoms

Biological parents married

Family economic hardship

\section{Young adulthood (W3)}

Depressive symptoms

Young adult status attainment

Relationship quality with father

Relationship quality with mother

Biological parents married

\section{Race/Ethnicity}

African American

$\begin{array}{ccc}-0.04 & -0.05 & -0.06 \\ (0.82) & (0.96) & (0.94) \\ 0.03 * * & 0.02 & 0.02 \\ (1.03) & (0.18) & (1.02) \\ 0.49 * * * & -0.40 & -0.33 \\ (1.64) & (0.67) & (0.72) \\ 0.14 * & 0.14 & 0.09 \\ (1.15) & (1.14) & (1.10)\end{array}$

Model $1 \quad$ Model $2 \quad$ Model 3

(1.15)

0.02

(1.02)

$-0.36 * * *$

(0.70)

$-0.07 * *$

(0.93)

$0.22 * * *$

(1.25)

$1.22 * * *$

(3.39)
0.01

(1.01)

$-0.35 * * *$

$(0.71)$

$-0.06^{*}$

(0.95)

$0.22 * * *$

(1.24)

$1.16^{* * * *}$

(3.19)

$0.89 * * *$

(2.43)

$0.99 * * *$

(2.69)

0.78 **

(2.18)

$* \mathrm{p}<.05 . \quad * * \mathrm{p}<.01 . \quad * * * \mathrm{p}<.001$. 
Figure 1

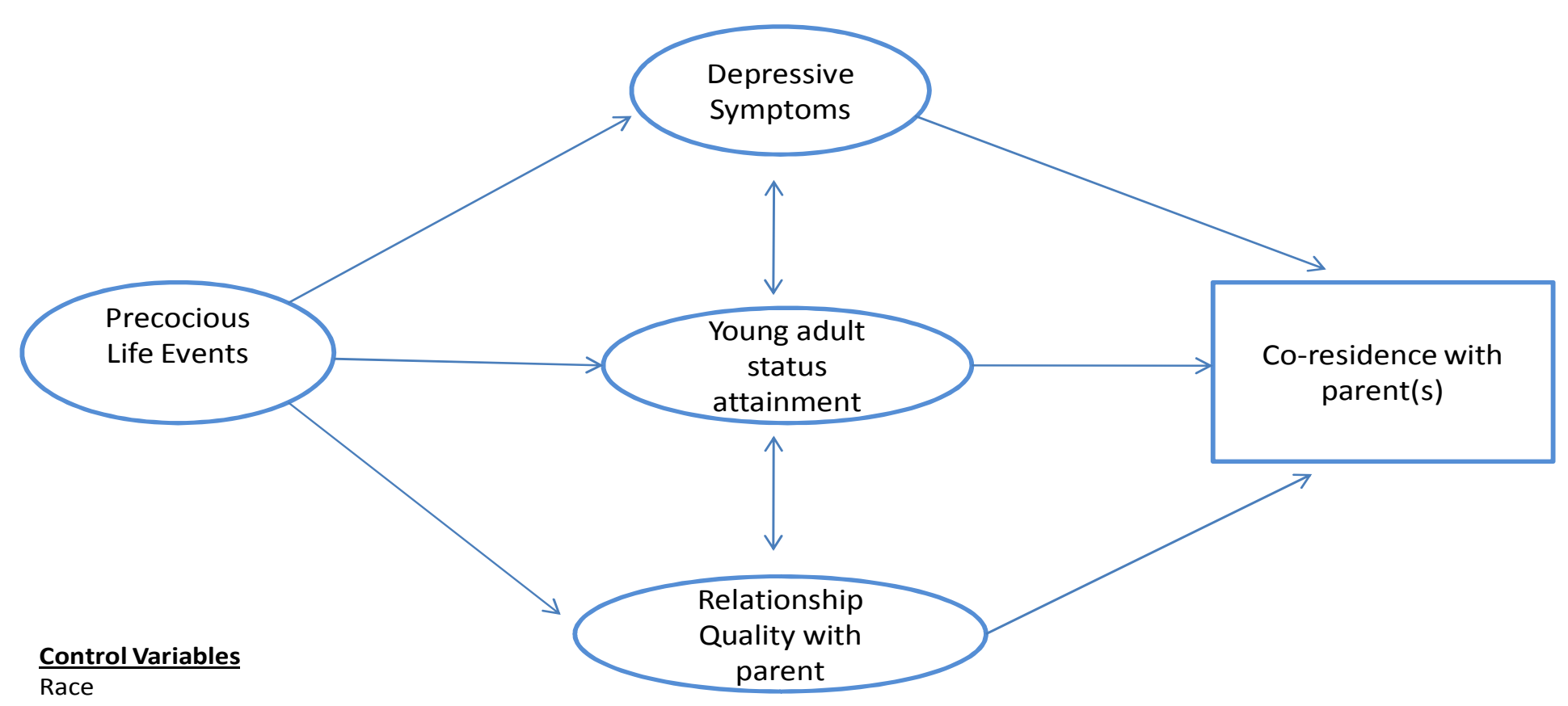

Biological parents married

Family economic hardship 
APPPENDIX A 


\section{Oklahoma State University Institutional Review Board}

\begin{tabular}{|c|c|c|}
\hline Date & Monday, August 29, 2011 & Protocol Expires: \\
\hline IRB Application No: & HE1067 & \\
\hline Proposal Title: & $\begin{array}{l}\text { Young Adults Who Live at Home: } \\
\text { Them There }\end{array}$ & The Precocious Events that Lead \\
\hline $\begin{array}{l}\text { Reviewed and } \\
\text { Processed as: }\end{array}$ & $\begin{array}{l}\text { Exempt } \\
\text { Continuation }\end{array}$ & \\
\hline
\end{tabular}

Status Recommended by Reviewer(s): Approved

Principal

invesêigator(s) :

Leslie Haughey

OSU Tulsa 700 N. Greenwood

Michael Merten

Tulsa, OK 74106

1111 Main Hall

Tulsa, OK 74106

Approvals are valid for one calendar year, after which time a request for continuation must be submitted. Any modifications to the research project approved by the IRB must be submitted for approval with the advisor's signature. The IRB office MUST be notified in writing when a project is complete. Approved projects are subject to monitoring by the IRB. Expedited and exempt projects may be reviewed by the full Institutional Review Board.

葍 The final versions of any printed recruitment, consent and assent documents bearing the IRB approval stamp are attached to this letter. These are the versions that must be used during the study.

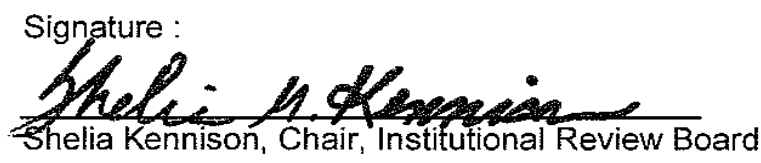

Monday, August 29, 2011

Date 
APPPENDIX B 
VITA

Leslie Haughey

Candidate for the Degree of

Master of Science

\section{Thesis: ADULTS WHO CO-RESIDE AND THE YOUNG ADULTHOOD FACTORS THAT LEAD THEM THERE}

Major Field: Human Development and Family Science

Biographical:

Education: Received Bachelor of Science degree in Human Development and Family Science from Oklahoma State University, Stillwater, Oklahoma in May 2008. Completed the requirements for the Master of Science in Human Development and Family Science at Oklahoma State University, Stillwater, Oklahoma in December 2011.

Experience: Employed by Oklahoma State University, Department of Human Development and Family Science as an undergraduate research assistant, 20062008; Oklahoma State University, Department of Human Development and Family Science as a graduate teacher's assistant, 2008-2010; Oklahoma State University, Department of Human Development and Family Science, as a graduate research assistant, January 2010-May 2010; Tulsa Educare, as a Family Advocate, 2010-present. 
Title of Study: ADULTS WHO CO-RESIDE AND THE YOUNG ADULTHOOD FACTORS THAT LEAD THEM THERE

Major Field: Human Development and Family Science

Scope and Method of Study: The purpose of this study was to examine the relationships between adolescent precocious life events and adults who co-reside at home. Data came from the National Longitudinal Study of Adolescent Health (Add Health), a longitudinal study of adolescents addressing their health behaviors and lifestyle is used for this study. Sample sized consisted of 10,061 individuals, and were assessed during adolescence (12-19 years old), young adulthood (18-26 years old) and adulthood (24-33 years old).

Findings and Conclusions: This study found that those individuals who co-reside in young adulthood are more likely to co-reside in adulthood, when compared to individuals who never co-resided in young adulthood. Relationship quality in young adulthood showed to impact the likelihood of co-residing in young adult and adulthood; with greater father quality decreases the likelihood for coresidency, whereas greater mother relationship quality increases. Males were more likely than females to co-reside in young adulthood and adulthood, along with African Americans, Hispanics and Asians being more likely to co-reside with parents during young adulthood and adult when compared to Whites. This study suggests that cultural beliefs and expectations may be an important component in co-residency, and relationship quality an important factor in the decision of residential status in adulthood.

ADVISER'S APPROVAL: Dr. Michael J. Merten 